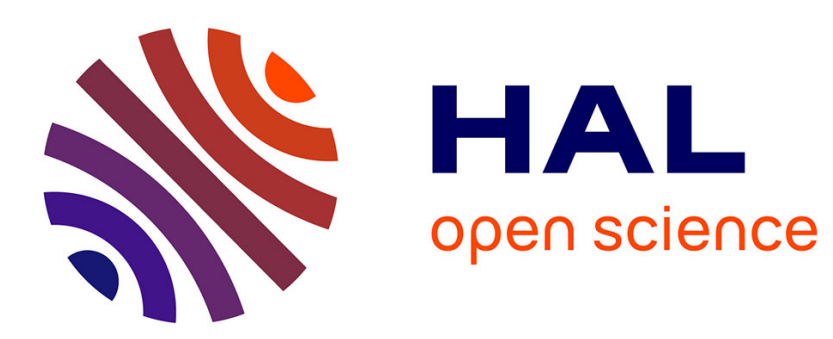

\title{
An Alternative Model to Basel Regulation
}

Sofiane Aboura, Emmanuel Lépinette

\section{To cite this version:}

Sofiane Aboura, Emmanuel Lépinette. An Alternative Model to Basel Regulation. 2013. hal00825018

\section{HAL Id: hal-00825018 \\ https://hal.science/hal-00825018}

Submitted on 19 Jul 2013

HAL is a multi-disciplinary open access archive for the deposit and dissemination of scientific research documents, whether they are published or not. The documents may come from teaching and research institutions in France or abroad, or from public or private research centers.
L'archive ouverte pluridisciplinaire HAL, est destinée au dépôt et à la diffusion de documents scientifiques de niveau recherche, publiés ou non, émanant des établissements d'enseignement et de recherche français ou étrangers, des laboratoires publics ou privés. 


\title{
An Alternative Model to Basel Regulation
}

\author{
Sofiane Aboura • Emmanuel Lépinette
}

\begin{abstract}
The post-crisis financial reforms address the need for systemic regulation, focused not only on individual banks but also on the whole financial system. The regulator's principal objective is to set banks' capital requirements equal to international minimum standards to minimize systemic risk. Indeed, the Basel agreement is designed to guide a judgment about minimum universal levels of capital and remains mainly microprudential rather than macroprudential in its focus.

An alternative model to the Basel framework is derived where systemic risk is considered in each bank's dynamic. This alternative be a new departure for prudential policy. It allows the regulator to compute capital and risk requirements for controlling systemic risk. Moreover, bank regulation is considered at two-scale levels, either the bank or at the system-wide level.

We test the adequacy of the model on a data set containing 19 banks of 5 major countries from 2005 to 2012. We compute the capital ratio thresholds per year for each bank and each country and rank them according to their level of fragility. Our results suggest considering an alternative measure of systemic risk that requires minimal capital ratios that are bank-specific and time-varying.
\end{abstract}

Keywords Systemic risk · Bank Regulation · Basel Accords

JEL Classification E44, E58, G01, G21, G28

\section{Introduction}

In the aftermath of the 2008 financial crisis, a growing consensus has emerged to strengthen the prudential rules covering the financial sector given the severe shock to the real economy. Reinhart and Rogoff (2009) show that financial crises are often associated with reductions in GDP of $10 \%$ or more. Indeed, Campello, Graham and Harvey (2010) find that the impact of the credit crisis was severe on financially constrained companies, leading to deep cuts in research, job creations, and investment. For that matter, a number of

S. Aboura

DRM-Finance, Paris-Dauphine University, Place du Maréchal De Lattre De Tassigny, 75775 Paris cedex 16, France

E-mail: sofiane.aboura@dauphine.fr

E. Lépinette

CEREMADE, Paris-Dauphine University, Place du Maréchal De Lattre De Tassigny, 75775 Paris cedex 16, France

E-mail: emmanuel.lepinette@ceremade.dauphine.fr 
institutions, including central banks, have been given the mission to measure systemic risk, control for financial vulnerabilities and safeguard the financial system.

Banks invest in portfolios composed by risky and risk-free assets. The banks finance these portfolios with borrowing funds that come from debt contracts (client deposits, issuance of bonds, equity). Risky investments are undertaken in any economic sector that fulfils the bank's profitability condition. By diversifying its risks, a bank lowers its own probability of failure. However, if banks diversify their risks in similar ways, then the probability of multiple failures can increase. Tarashev, Borio, and Tsatsaronis (2009) find that the systemic importance of an institution increases in its size as well as in its exposure to common risk factors. As more banks fail simultaneously, the economic disruption tends to increase disproportionately. Indeed, correlated investments may induce excessive asset growth, which can turn out to be a bubble, likely to enhance the financial sector vulnerabilities. Systemic risk can arise when the bank portfolios are strongly correlated or when the interconnectedness of banks is too high. Systemic risk can be defined as a bank failure propagation that causes the failure of other banks or other firms. More precisely, Acharyaa (2009) defines systemic risk as the joint failure risk arising from the correlation of returns on the asset side of bank balance sheets. Contagion is the manifestation of systemic risk. De Bandt and Hartmann (2000) provide a review of the literature on contagion. Allen and Gale (2000) propose a model of contagion through a network of interbank exposures. Karolyi (2003) gives an analysis of different approaches to define and measure contagion. Elsinger, Lehar and Summer (2006) explain the contagion phenomenon as the correlation in banks' asset portfolios in the Austrian banking sector.

Some studies discuss the calculation method of systemic risk; among these studies is literature on the extreme value theory. This literature includes two interesting studies. First, Hartmann, Straetmans and De Vries (2005) use multivariate extreme value theory to estimate the systemic risk in the US and European banking systems. Second, Acharya, Pedersen, Philippon and Richardsony (2010) show that each financial institution's contribution to systemic risk can be measured as its systemic expected shortfall. In the same spirit, Engle, Jondeau and Rockinger (2012) measure systemic risk as the propensity of a financial firm to be undercapitalized when the financial system as a whole is undercapitalized. Using graph theory in a static approach, Cont, Moussa and Santos (2010) focus on the interconnectedness of the institutions. Minka and Amini (2012) set up a network model that accounts for insolvency cascades.

Nevertheless, a bankruptcy induces conflicting effects on surviving banks. The first effect represents the negative externality that takes the form of a recessionary effect to the real economy, which mechanically affects the survivors through an increase in the risk premia and a decline in the liquidity. Diamond and Rajan (2005) explain that a bank exposed to a liquidity shock is forced to sell assets due to the hardness of deposit contracts: however, in the process, that bank reduces the aggregate liquidity available to other banks, causing a rise in their costs of borrowing and a reduction in value. Shin (2008) develops a theory of liquidity spillover across a network of financial institutions resulting from expansions and contractions of balance sheets over the credit cycle. The second effect represents the windfall effect arising from the failure of other banks that mechanically brings market shares to the survivors.

In addition, the systemic risk effect concern the whole economy. This effect induces various costs that require a distinction between costs to individual institutions usually called private costs and costs to the real economy usually called social costs. The sum of private and social costs represents the real cost of a bank failure.

On March 10, 2009, Ben S. Bernanke, chairman of the Federal Reserve, suggested that "capital regulations require that banks' capital ratios meet or exceed fixed minimum standards for the bank to be considered safe and sound by regulators...supervisors also must ensure that organizations have the ability to assess their overall capital needs and hold capital commensurate with their individual risk profiles." 
Capital requirement is defined as the amount of capital a bank has to hold to ensure that it can face losses from any investment to avoid a default risk. The cornerstone of the international regulatory agenda is the setting of higher requirements for banks' capital to reduce idiosyncratic risks of individual banks and consequently lessen the risk of defaults cascading around the financial system. Furthermore, Morrison and White (2005) recall the role that capital requirements play in terms of moral hazard; indeed, if a bank does not have enough equity at stake when it makes its investments, it may take decisions that are optimal for equity holders but sub-optimal for the rest of the stakeholders. Brei, Gambacort and Von Peter (2012) find that bank capitalization plays an important role in supporting bank lending, i.e., sustaining the economy. In the same spirit, Diamond and Rajan (2012) explain how central banks can reduce financial fragility using interest rate policy to combat illiquidity in the banking sector.

The Basel Committee decided to reinforce the capital adequacy framework within the Basel III agreement on banking supervision in 2010. The main focus is overall micro prudential. Basel agreements are designed to limit each institution's individual risk seen apart. The aim of the capital ratio adequacy is to protect the banks, their clients and the national economy. More precisely, the capital ratio is the percentage of a bank's capital to its risk-weighted assets. Basel III requires banks to hold $4.5 \%$ of common equity and $6 \%$ of Tier I capital ${ }^{1}$ of risk-weighted assets from 2015 . Basel III also introduces additional increasing capital buffers from 2016 to 2019: first, a mandatory capital conservation buffer of $2.5 \%$ to absorb losses during periods of financial stress. The capital conservation buffer must be met exclusively with common equity, bringing the total common equity requirement to $7 \%$ in 2019 . The non-respect of the capital conservation buffer is likely to induce restrictions on dividend payments, share repurchases and bonus packages. The second buffer is a discretionary counter-cyclical buffer during periods of expansion that allows local regulators to demand up to additional $2.5 \%$ of capital from 2016. The purpose of the countercyclical buffer is to protect the banking sector from periods of excess credit growth. This buffer can be seen as an extension of the conservation buffer. The overall capital requirement (i.e., minimum total capital plus conservation buffer) will increase from $8 \%$ to $10.5 \%$ from 2013 to 2019 . However, excessive leverage by banks is widely believed to have contributed to the global financial crisis. For that reason, Basel III additionally introduces a minimum leverage ratio along with two required liquidity ratios. However, Schanz (2011) find that high capital ratios may be able to substitute for high liquidity ratios ${ }^{2}$.

Setting capital requirements raises two fundamental questions. First, what is, at the banking sector level, the total amount of capitalization required to withstand a shock? Second, what is, at the bank level, the capital requirement that equals its contribution to systemic risk? Answering these questions requires discussing the capital ratio requirement and the systemic risk. We believe it is not so clear that imposing a uniform minimum capital requirement is the unique way to control systemic risk.

The regulator can be a legal authority with binding rules (central bank, market authority) or professional non binding authority (Basel Committee). The current scheme appears to give more regulative power to central bankers. The regulator's objective is to maximize the sum of the welfare of the government, the depositors and the bank owners.

Bank regulation through capital requirement has pros and cons. Regulation brings some substantial advantages to individual banks such as recapitalizations through ad-hoc structures (e.g., TARP in the U.S., ESM in the E.U., the government shareholding company (SPPE) in France), asset purchase/lending (e.g., Central banks (Fed, ECB, BoE, BoJ), EFSF and ESM in the E.U.) or insurance schemes in terms of

\footnotetext{
1 Tier 1 capital is defined as the sum of capital and reserves minus some intangible assets such as goodwill.

2 The leverage ratio, which should be in excess of $3 \%$, is calculated by dividing Tier 1 capital by the bank's average total consolidated assets. The short term 'liquidity coverage ratio' requires a bank to hold enough high-quality liquid assets to cover its total net cash outflows over the next 30 days. The middle-long term 'net stable funding ratio' requires the available amount of stable funding to exceed the required amount of stable funding over a next one-year period.
} 
deposit insurance or debt guarantees (central banks, governments) that are typically tailored to individual companies. Gauthier, Lehar, and Souissi (2010) note that systemic capital allocation mechanisms reduce default probabilities of individual banks as well as the probability of a systemic crisis by approximately $25 \%$. Philippon and Schnable (2013) find that preferred stocks plus standard warrants significantly outperform pure equity injections in the U.S. case.

However, there are four possible drawbacks of the regulation through Basel capital ratios. First, the introduction of a capital ratio may foster a bank to set up large off-balance-sheet exposures. Second, the capital ratio may amplify the business cycles because a bank might reduce its lending during a recession to satisfy the Basel capital ratio. Slovik and Cournde (2011) evaluate the impact of the Basel III implementation on GDP growth in a range of -0.05 to -0.15 percentage points per year. Third, the capital ratio may reduce the value of a bank for two reasons related to the government. The first reason is related to debt financing, which has a tax advantage over equity capital because debt interests can be partially deducted from profits. Under such regulation, the bank present value is reduced given that increasing the equity part of the capital structure means reducing the tax shield offered by the government. The second reason is related to the government guarantee on the bank assets. The Basel committee requires banks to have a higher capital ratio, which mechanically reduces the government guarantee on the bank assets, decreasing the bank present value. Furthermore, moral hazard may play a dangerous role. Indeed, the Basel capital requirement ratio is indirectly related to the debt ratios. However, this raises an important question on why banks have very high debt ratios in contrast to other economic sectors. In fact, because banks are strongly regulated, they may feel more protected (due to the too-big-to-fail argument) than most other firms. Consequently, this might contribute to increased risk taking typically through innovative derivative products. Additionnally, Bertrand, Schoar and Thesmar (2007) find that a lowering of French state regulation in the banking sector was accompanied by a more efficient allocation of bank loans.

In addition, some improvements remain possible for adapting capital requirements to multiple situations. Indeed, the Basel capital requirement should be different from country to country, because the economic structures, banking systems (universal versus pure players), institutions stock prices or economic growth rates differ. For example, Yoshino, Hirano and Miura (2009) suggest that the Basel capital requirement should depend on the banking behavior, the macroeconomic structure in each country and the impact of economic shocks on each economy. More particularly, the Basel capital requirement ratio should vary during a period of economic upturn and during a period of economic downturn. Generally, banks do not necessarily need to raise capital during an economic upturn. In contrast, banks need to do so during economic downturns. However, during a recession, raising capital turns out to be costly because stock prices are low. Therefore, a bank should raise capital during an expansion cycle so as to prepare for bad times. Thus, if regulation is designed counter cyclically, with buffers rising in upturns and falling in downturns, this approach would reduce systemic risk for two reasons. First, such regulation enhances insurance during expansion cycles so as to increase system-wide resilience against negative externalities. Second, such regulation creates an incentive for banks to control risk taking during good times. However, increasing the capital requirement during a boom might drive the banks to shift toward the shadow banking sector where they take much more risk. Furthermore, Kim and Mangla (2012) suggest that the capital requirement needs to be relaxed in good times to prevent the banks from running into shadows. As a consequence, a bank has a trade-off between the benefit of regulation such as an almost free insurance and the associated costs such as constraints on risk taking. This tradeoff gives rise to the determination of an optimal capital ratio. Miles, Yang and Marcheggiano (2011) find for the U.K. banks that the optimal capital should be approximately $20 \%$ of risk-weighted assets. More recently, Kragh-Srensen (2012) find that the Norwegian banks' equity Tier 1 ratio should be between $13 \%$ and $23 \%$. 
In addition to the Basel capital requirement ratio, there is an ongoing debate on the usefulness of splitting banks. This system might be an alternative to the capital requirement. There are two possibilities. First, limit the size to curb the magnitude of the cascade effects following a systemic failure. Second, limit the activities to isolate the potential for inside contamination within banks. Some main reforms were engaged in the main countries (The U.S. Dodd-Frank Wall Street Reform and Consumer Protection Act (2010) subsides hedge funds, private equity and proprietary trading from the other banking business. The U.K. Vickers report (2011) quarantines speculative activities from other banking businesses. The U.E. Liikanen report (2012) suggests that proprietary trading should be assigned to a separate legal entity from a given threshold.). The optimal size of a bank has been treated by some authors such as Krasa and Villamil (1992) who argue that the monitoring costs borne by equity holders rise more than linearly with the size of the portfolio. The authors conclude that as the bank increases in size, the marginal cost of raising equity capital rises. Cerasia and Daltungb (2000) derive an optimal bounded size of the bank by linking the benefits of diversification to the costs.

Therefore, systemic risk has received considerable attention since the 2008 financial crisis. Notably, few previous studies examined jointly the micro and macro prudential perspectives of capital ratio requirement, while this approach is the key point to allow for a regulation that minimizes the three main adverse effects (profitability, credit constraint and shadows). Indeed, the main Basel rule is designed to guide a judgment about minimum acceptable levels of capital. Little progress has been made so far in addressing these issues in a comprehensive way. This article brings new insight by providing the regulator with a simple model able to compute a time-varying capital ratio adequacy for each bank and each country. The model considers systemic risk in terms of recovery rates from which it derives three new indicators for banks characterizing fragility, immunity and capital ratio threshold. The model is tested on a dataset of 19 banks of 5 major countries from 2005 to 2012. The results confirm the relevance of the model. In particular, the fragility indicator appears to be a leading indicator for a financial crisis.

The article is organized as follows. Section 2 develops the model for banking regulation. Section 3 presents the data, and section 4 discusses the empirical results and policy implications. Finally, Section 5 summarizes the main findings.

\section{The Model}

\subsection{Basic Notations}

Let $\left(\Omega, \mathcal{F}, \mathbb{F}=\left(\mathcal{F}_{t}\right)_{t=0,1, \cdots, T}\right)$ be a complete discrete-time stochastic basis. The financial system we consider contains $N_{t}$ firms at time $t$ we denote by $1, \cdots, N_{t}$. If $X$ is an adapted stochastic process, which we denote $\Delta X_{t}:=X_{t}-X_{t-1}$ and $R_{t}^{X}:=\Delta X_{t} / X_{t-1}$. If $\mathcal{H}$ is a sub- $\sigma$-algebra and $A$ is a set in a measurable space, $L^{0}(\mathcal{H}, A)$ is the set of all $A$-valued $\mathcal{H}$-measurable random variables. We suppose that each firm number $i$, $i=1, \cdots, N_{t}$, has only a partial information modeled by a filtration $\left(\mathcal{F}_{t}^{i}\right)_{t=0,1, \cdots, T}$ such that $\mathcal{F}_{t}^{i} \subseteq \mathcal{F}_{t}$ for all $i$.

\subsection{Dynamics of Assets}

At any time $t$, let us consider a generic firm $i$. This firm is characterized by an $\mathcal{F}_{t}^{i}$-adapted process $Z_{t}^{i} \in$ $\mathbf{R}^{2}$ such that $Z_{t}^{i 1}=: A_{t}^{i} \geq 0$ is the amount expressed in numéraire of the asset account and $Z_{t}^{i 2}=: D_{t}^{i} \geq 0$ is the value of the liability account. In the following, we use $E_{t}^{i}:=A_{t}^{i}-D_{t}^{i}$ to indicate the shareholder equity. 
We suppose that the net return of the investment activity of firm number $i$ is modeled by an asset $a_{t}^{i}>0$ such that the return $R_{i, t}^{A}:=\Delta a_{t}^{i} / a_{t-1}^{i}=\left(a_{t}^{i}-a_{t-1}^{i}\right) / a_{t-1}^{i}>-1$ is the average of the net returns of the risky investments weighted by the investment rates the manager has chosen at time $t-1$. This assumption means that if $S^{i j}>0, j=1, \cdots, d^{i}$, are strictly positive processes modeling the dynamics of the risky investments chosen at time $t-1$ in the composition of $A_{t-1}^{i}$, then

$$
R_{i, t}^{A}=\sum_{j=1}^{d^{i}} x_{j}^{i}(t)\left(\Delta S_{t}^{i j} / S_{t-1}^{i j}\right)
$$

where $x_{j}^{i}(t) \in L^{0}\left(\mathcal{F}_{t-1}^{i},[0,1]\right)$ and $\sum_{j=1}^{d^{i}} x_{j}^{i}(t)=1$.

We suppose that $R_{i, t}^{A}$ is the value of a theoretical random return that the firm $i$ obtains by using a calibration method at time $t-1$; The firm models what should be the return of its investment for the next period. This means that we assume the following common belief: each firm agent at time $t-1$ rebalances his portfolio of assets by choosing risky investments he believes to be fail-safe, i.e., without any possibility of bankruptcy or huge fair value depreciation. This is the case when the risky assets $\left(S^{i j}\right)$ that form the portfolio of firm $i$ are modeled by geometric Brownian motions because they are strictly positive. In this case, failures of such stocks are not taken into consideration or, at least, do not correspond to the zero value of the shares. In fact, prices are only statistically observed strictly before they hit zero meaning that we can only get samples that are conditioned to the fact that there is no failure. In the CAPM model, the two-funds theorem allows us to characterize an efficient portfolio process of return $R_{i, t}^{A}$ as

$$
R_{i, t}^{A}=x_{0}^{i}(t) R^{0}(t)+\left(1-x_{0}^{i}(t)\right) R^{M}(t)
$$

where $R^{M}$ is the return of the so-called market portfolio and $R^{0}$ is the riskless rate of the market. Here, we assume that $x_{0}^{i}(t) \in L^{0}\left([0,1], \mathcal{F}_{t-1}\right)$, i.e. there are no short positions. Assuming that $R^{0}>-1$ and $R^{M}>-1$, we deduce that $R_{i, t}^{A}>-1$. We may also modify (2.2) to consider that the manager aims to reach, as minimal return, the weighted average cost of capital, i.e.

$$
R_{i, t}^{A}=\max \left(x_{0}^{i}(t) R^{0}(t)+\left(1-x_{0}^{i}(t)\right) R^{M}(t) ; \frac{R_{i, t}^{D} D_{t-1}^{i}+R_{i, t-1}^{E} E_{t-1}^{i}}{D_{t-1}^{i}+E_{t-1}^{i}}\right) .
$$

We aim to consider the fact that it is very difficult to capture, in the classical models, a rare event such as a sudden depreciation of some assets. Therefore, we model the dynamics of the asset account $A^{i}$ by adding a multiplicative recovery rate $T_{t}^{i}$ such that $1-T_{t}^{i}$ is the default rate; If $T_{t}^{i}=80 \%$, this means that firm number $i$ loses $20 \%$ of the value $A_{t}$ (before consumption and transfers) estimated by the theoretical return $R_{t}^{A}:=\Delta I_{t}^{i} / I_{t-1}^{I}$. Precisely, we suppose that

$$
A_{t}^{i}=A_{t-1}^{i}\left(1+R_{i, t}^{A}\right) T_{t}^{i}+\Delta L_{t}^{i}+\Delta \tilde{L}_{t}^{i}-\Delta C_{t}^{i}
$$

where $\Delta L_{t}^{i}$ (resp. $\Delta \tilde{L}_{t}^{i}$ ) is the net cumulated transfer of money from account $D_{t}^{i}$ (resp. $E_{t}^{i}$ ) to account $A_{t}^{i}$. In the case where $\Delta L_{t}^{i} \leq 0$ (resp. $\left.\Delta \tilde{L}_{t}^{i} \leq 0\right)$, this means that the agent reimburses at time $t$ a part of the debt $D_{t-1}^{i}\left(1+R_{i, t}^{D}\right)$ where $R_{i, t}^{D}:=\Delta S_{i, t}^{D} / S_{i, t-1}^{D} \geq 0$ models the interest rate for the debt $D^{i}$ (resp. the 
agent repurchases its issued stocks). Otherwise $\Delta L_{t}^{i} \geq 0$ (resp. $\left.\Delta \tilde{L}_{t}^{i} \geq 0\right)$ means that the agent increases the volume of the investments by borrowing more through bond issuance (resp. the agent issues new stocks). Therefore, we suppose the following dynamics:

$$
\begin{aligned}
\Delta D_{t}^{i} & =D_{t-1}^{i} R_{i, t}^{D}+\Delta L_{t}^{i}, \\
\Delta E_{t}^{i} & =E_{t-1}^{i} R_{i, t}^{E}+\Delta \tilde{L}_{t}^{i}
\end{aligned}
$$

where $R_{i, t}^{E}:=\Delta S_{i, t}^{E} / S_{i, t-1}^{E}$ is the return of the shareholder equity and $S_{i, t}^{E}$ is the stock market price at time $t$. Moreover, $\Delta C_{t}^{i}$ designates the total amount of dividend delivered by firm $i$ at time $t$. Note that $R_{i}^{D}$ is the borrowing cost of firm $i$.

Remark 2.1 Observe that it is usual to model the dynamic of an investment position $A$ by $\Delta A_{t}=R_{i, t}^{A} A_{t-1}$ where $R_{i, t}^{A}$ is the associated return. This means that the process $A$ is self-financing, i.e., there is no addition or withdrawal of wealth in time (i.e., no extra investment or reimbursement and consumption). This assumption is clearly in contradiction with reality. In the following, we use $R_{i, t}^{A d}$ to indicate the return including investment defaults. It is defined by the equation

$$
\left(1+R_{i, t}^{A}\right) T_{t}^{i}=: 1+R_{i, t}^{A d}
$$

Remark 2.2 From the dynamics above, we deduce that

$$
A_{t-1}^{i}\left(\left(1+R_{i, t}^{A}\right) T_{t}^{i}-1\right)=D_{t-1}^{i} R_{i, t}^{D}+\Delta C_{t}^{i}+E_{t-1}^{i} R_{i, t}^{E}
$$

or equivalently

$$
E_{t-1}^{i} R_{i, t}^{E}=A_{t-1}^{i}\left(\left(1+R_{i, t}^{A}\right) T_{t}^{i}-1\right)-D_{t-1}^{i} R_{i, t}^{D}-\Delta C_{t}^{i}
$$

This equation corresponds to the weighted average cost of capital where dividend paiements are explicit in the case $T_{t}^{i}=1$. This equation means that the stock holder wealth increment $E_{t-1}^{i} R_{i, t}^{E}$ is computed from the operating profit once the stock dividends $\Delta C_{t}^{i}$ and the bond interests $D_{t-1}^{i} R_{i, t}^{D}$ are paid.

Remark 2.3 Observe that we may also deduce the dynamics of $E=A-D$ as:

$$
\begin{aligned}
& \Delta E_{t}^{i}=A_{t-1}^{i}\left(\left(1+R_{i, t}^{A}\right) T_{t}^{i}-1\right)-\Delta C_{t}^{i}+\Delta \tilde{L}_{t}^{i}-D_{t-1}^{i} R_{i, t}^{D}, \\
& \Delta E_{t}^{i}=A_{t-1}^{i}\left(\left(1+R_{i, t}^{A}\right) T_{t}^{i}-R_{i, t}^{D}-1\right)-\Delta C_{t}^{i}+\Delta \tilde{L}_{t}^{i}+E_{t-1}^{i} R_{i, t}^{D} .
\end{aligned}
$$

\subsection{Recovery Rate Associated to Large Depreciation}

In the following, we consider the sequence $\alpha^{k}:=10 k / 100, k=1, \cdots, 10$, and we put $\alpha^{11}:=+\infty$. We fix $m \in\{1, \cdots, 10\}$ such that the threshold $\alpha:=\alpha_{m} \in(0,1]$ represents the minimal loss rate $-\Delta E_{t}^{i} / E_{t-1}^{i}=$ $\left|\Delta E_{t}^{i}\right| / E_{t-1}^{i}$ above, which we consider the depreciation of $E^{i}$ that is not captured by the dynamic modeling of the process $E^{i}$. If the loss is complete $(\alpha=1), E_{t-1}^{i}>0$ and $\Delta E_{t}^{i} / E_{t-1}^{i} \leq-\alpha$, i.e., $\Delta E_{t}^{i} \leq-E_{t-1}^{i}$ or equivalently $E_{t}^{i} \leq 0$, then the firm goes bankrupt.

Definition 2.4 We say that firm $i$ fails at time $t$ if $E_{t-1}^{i}>0$ and $\Delta E_{t}^{i} / E_{t-1}^{i} \leq-\alpha$; we use $\tau_{t}^{i}$ as the indicator function equal to one when failure holds. 
Remark 2.5 Such failure means that $E_{t-1}^{i}>0, \Delta E_{t}^{i}<0$ and $\left|\Delta E_{t}^{i}\right| / E_{t-1}^{i} \geq \alpha$. Fixing $\alpha$ close to 1 should oblige the firm to more consider unexpected 'large' drops of the market and therefore prevent them from unexpected losses. Of course, some sophisticated models aim to include large jumps (e.g., using Levy processes, Pareto processes); however, it turns out to be difficult to calibrate models to real financial data when rare events, i.e., not statistically observable, fail to be captured. The recent financial crisis appears to confirm the weakness of the existing models in anticipating large drops.

We denote by $X_{t}^{i} \in L^{0}\left(\mathcal{F}_{t-1}^{i},[0,1]\right)$ the recovery rate associated with the stocks issued by firm $i$

$$
X_{t}^{i}=1_{\left\{\tau_{t-1}^{i}=0\right\}}+1_{\left\{\tau_{t-1}^{i}=1\right\}} \sum_{k=m}^{10}\left(1-h^{i}\left(\alpha^{k}\right)\right) 1_{\alpha_{k+1} \geq\left|\Delta E_{t-1}^{i}\right| / E_{t-2}^{i} \geq \alpha_{k}},
$$

where $h^{i} \in(0,1]$ is a function specific to firm $i$. Precisely, we suppose that $h^{i}\left(\Delta E_{t}^{i} / E_{t-1}^{i}\right)$ is the market value of the equity return while $\Delta E_{t}^{i} / E_{t-1}^{i}$ is the equity return of the balance sheet. Studying the nature of $h^{i}$ is beyond the scope of the paper. The equation (2.11) means that if a given firm bought at time $t-1$ shares issued by firm $i$, then at time $t$, it only recovers the rate $X_{t}^{i}$ of the wealth modeled at time $t-1$ by a stock price dynamic that does not consider the large depreciation characterized by the failure $\left|\Delta E_{t-1}^{i}\right| / E_{t-2}^{i} \geq \alpha$. For instance, if $\left|\Delta E_{t-1}^{i}\right| / E_{t-2}^{i} \in[80 \%, 90 \%]$, then a firm having invested in firm $i$ recovers only $20 \%$ of the estimated wealth at time $t$ in the case where $h^{i}(x)=x$.

We suppose that the information on failures is delayed, i.e., when some firm fails strictly after time $t-1$ but before $t$, the information is only given to the other firms of the system at time $t$. Precisely, we suppose that $X_{t}^{i} \notin L^{0}\left(\mathcal{F}_{t-1}^{j}\right)$ for all $j \neq i$ and $X_{t}^{i} \in L^{0}\left(\mathcal{F}_{t-1}^{i}\right)$ for all $i$. It is natural to define $T_{t}^{i}$ as the weighted recovery rate

$$
T_{t}^{i}:=\sum_{j=1}^{d^{i}} x_{j}^{i}(t) X_{t}^{n(i j)}
$$

where $n(i j)$ is the number of the firm that has issued asset $S^{i j}$ while $x_{j}^{i}(t)$ is the proportion invested by firm $i$ in risky assets $S^{i j}$ (see Formula (2.1)).

\subsection{Bank Specific Regulation}

Our model may be applied to any type of firm; however, hereafter, we restrict our model to the banking sector. Indeed, it is commonly accepted that systemic risk is caused by a banking crisis ${ }^{3}$. We propose three specific systemic risk indicators at the bank level, which are deduced from the following.

Lemma 2.6 Suppose that $\Delta C_{t}^{i}=\Delta \tilde{L}_{t}^{i}=0$ when the bank $i$ fails at time $t$, i.e. no dividend is paid and there is no cash transfer from asset to equity. Then, the failure of bank $i$ occurs at time $t$ when the following equivalent conditions hold:

$$
\begin{gathered}
E_{t-1}^{i}>0 \text { and } \Delta E_{t}^{i} / E_{t-1}^{i} \leq-\alpha \\
\Leftrightarrow 0<\frac{E_{t-1}^{i}}{A_{t-1}^{i}} \leq \Re_{t}^{i}, \\
\Leftrightarrow T_{t}^{i} \leq T_{t}^{* i},
\end{gathered}
$$

3 The 2012 Liikanen report mentions that "the risk-taking was not matched with adequate capital protection, and strong linkages between financial institutions created high levels of systemic risk". 
where

$$
\begin{aligned}
\Re_{t}^{i} & :=\frac{1+R_{i, t}^{D}-\left(1+R_{i, t}^{A}\right) T_{t}^{i}}{R_{i, t}^{D}+\alpha}, \\
T_{t}^{* i} & :=\frac{1+R_{i, t}^{D}-\frac{E_{t-1}^{i}}{A_{t-1}^{i}}\left(\alpha+R_{i, t}^{D}\right)}{\left(1+R_{i, t}^{A}\right)}, \\
& :=\frac{1+R_{i, t}^{D}-\frac{E_{t-1}^{i}}{A_{t-1}^{i}}\left(\alpha+R_{i, t}^{D}\right)}{\left(1+R_{i, t}^{A d}\right)} T_{t}^{i} .
\end{aligned}
$$

Remark 2.7 By virtue of (2.13), the indicator $\Re^{i}$ given by (2.14) is the capital ratio threshold below which bank $i$ fails at time $t$, i.e., the higher $\Re^{i}$ is, the more fragile bank $i$ should be for a given ratio $E_{t-1}^{i} / A_{t-1}^{i}$. The coefficient $\left(1+R_{i, t}^{A d}\right)$ is easily observable by the bank $i$ because $R_{i, t}^{A d}$ corresponds to the return of $A$, including the defaults but before transfers and dividend payments. Similarly, $T_{t}^{i}$ is easily observable. Note that $T_{t}^{* i}$ turns out to be a fragility indicator given by Formula (2.15).

Remark 2.8 At time $t-1$, given the laws of $\left(X_{t}^{j}\right)_{j}$, the manager of bank $i$ can deduce the law of $T_{t}^{i}$ as a function of his investment strategy given by the proportions $\left(x_{j}^{i}(t)\right)_{j}$. Given a theoretical dynamic of $R_{i, t}^{A}$ and an estimation of the return $R_{i, t}^{D}$, the agent deduces the law of $\Re_{t}^{i}$ and may choose a strategy $x^{i}:=\left(x_{j}^{i}(t)\right)_{j}$ such that $E_{t-1}^{i} / A_{t-1}^{i} \geq \Re_{t}^{i}$ with a probability greater than $1-\epsilon$, for some $\epsilon>0$ to be fixed. This means that the agent constraint is $F_{\Re_{t}^{i}}\left(E_{t-1}^{i} / A_{t-1}^{i}\right) \geq 1-\epsilon$ where $F_{\Re_{t}^{i}}$ is the cumulative distribution of $\Re_{t}^{i}$ which depends on the strategy $x^{i}$. This first approach given by $\Re_{t}^{i}$ agrees with the capital ratio requirement in the setting of the Basel Accords.

Remark 2.9 On the one hand, the manager may not select too many risky assets by choosing the strategy $x$ such that $T_{t}^{i} \geq T_{t}^{* i}$ with probability greater than $1-\epsilon$. To do so, it is sufficient to know the laws of the random variables $\left(X_{t}^{j}\right)_{j}$ revealed by rating agencies and then use Formula 2.12. Thus, by selecting assets with low default probabilities, the manager ensures the increase of the recovery rate.

On the other hand, he may act on $T_{t}^{* i}$; precisely, it is possible to lower it by increasing the ratio $E_{t-1}^{i} / A_{t-1}^{i}$. Actually, by choosing non-risky investments, he increases $T_{t}^{i}$; however, $R_{i, t}^{A}$ should simultaneously be lowered, which should mechanically enhance $T_{t}^{* i}$, i.e., $T_{t}^{i}$ and $T_{t}^{* i}$ are monotonic. The inequality $T_{t}^{i} \geq T_{t}^{* i}$ reads as

$$
W_{i, t} \geq 1+R_{i, t}^{D}-\frac{E_{t-1}^{i}}{A_{t-1}^{i}}\left(\alpha+R_{i, t}^{D}\right)
$$

where $W_{i, t}:=1+R_{i, t}^{A d}$. Observe that $W_{i, t}$ can be interpreted as the terminal wealth of the bank investment starting from a unit of initial endowment. Notice that in the usual models, $W_{i, t}$ is restricted to $W_{i, t}=1+R_{i, t}^{A}$. Solving the following inequation

$$
P\left(W_{i, t} \geq 1+R_{i, t}^{D}-\frac{E_{t-1}^{i}}{A_{t-1}^{i}}\left(\alpha+R_{i, t}^{D}\right)\right) \geq 1-\epsilon, \quad \epsilon>0
$$

is equivalent to say that $1+R_{i, t}^{D}-\frac{E_{t-1}^{i}}{A_{t-1}^{i}}\left(\alpha+R_{i, t}^{D}\right)$ is the Value-at-Risk of $W_{i, t}$ of order $\epsilon$ and one year maturity. Because $R_{i, t}^{D}$ is supposed to be $\mathcal{F}_{t}^{i}$ measurable, we then deduce the minimal capital requirement $\Re_{t-1}^{i, \epsilon}$ of order $\epsilon$ for the ratio $\frac{E_{t-1}^{i}}{A_{t-1}^{i}}$ : 


$$
\Re_{t-1}^{i, \epsilon}:=\frac{1+R_{i, t}^{D}-\operatorname{VaR}\left(W_{i, t}\right)}{\alpha+R_{i, t}^{D}} \in L^{0}\left(\mathcal{F}_{t-1}^{i}\right) .
$$

Contrary to the random threshold capital ratio $\Re_{t}^{i}$, the indicator $\Re_{t-1}^{i, \epsilon}$ is deterministic at time $t-1$. This fact means that the supervisor may require the manager to compute this bank-specific indicator such that the condition $P\left(T_{t}^{i} \geq T_{t}^{* i}\right) \geq 1-\epsilon$ holds, i.e., there is no failure of bank $i$ with a probability greater than $1-\epsilon$.

Remark 2.10 If we denote by $\Re^{\text {Basel }}$ the minimal requirement capital ratio imposed by the Basel accords for $E_{t-1}^{i} / A_{t-1}^{i}$, we obtain that

$$
T_{t}^{* i} \leq \frac{1+R_{i, t}^{D}-\Re^{\text {Basel }}\left(\alpha^{d}+R_{i, t}^{D}\right)}{1+R_{i, t}^{A}} .
$$

If $R_{i, t}^{A} \geq R_{i, t}^{D}$ a.s. we deduce that

$$
T_{t}^{* i} \leq 1-\Re^{\text {Basel }} \frac{\left(\alpha^{d}+R_{i, t}^{D}\right)}{\left(1+R_{i, t}^{D}\right)} .
$$

In particular, $T_{t}^{* i} \leq 1-\Re^{\text {Basel }}$ when $\alpha=1$, i.e. the uniform Basel ratio $\Re^{\text {Basel }}$ is a lever to uniformly decrease $T_{t}^{* i}$ and then reinforce the immunity of each bank against bankruptcy.

Remark 2.11 Observe that it is natural to suppose that $T_{t}^{* i}<1$ a.s. because $T_{t}^{i} \leq 1$ by definition. This provides precious insight into how to model the dynamics $R_{i, t}^{A}$. The latter must satisfy the following:

$$
\left(1+R_{i, t}^{A}\right)>1+R_{i, t}^{D}-\frac{E_{t-1}^{i}}{A_{t-1}^{i}}\left(\alpha^{d}+R_{i, t}^{D}\right),
$$

on the set $R_{i, t}^{A}>-1$, which is of full measure in our model ${ }^{4}$. Notice that Inequality (2.17) holds when $R_{i, t}^{A} \geq R_{i, t}^{D}$.

Remark 2.12 It is interesting to compute the quantity $\mathcal{I}^{i}:=T_{t}^{i}-T_{t}^{* i}$ which measures the immunity of each bank against default. Indeed, the larger the algebraic distance $T_{t}^{i}-T_{t}^{* i}$ is, the better the bank is immunized.

We propose a capital adequacy ratio threshold specific to each bank. This ratio may be compared to the uniform capital requirement ratio imposed by the Basel regulation. In our case, a uniform lower bound $\mathcal{I}^{*}$ for the immunity indicators $\left(\mathcal{I}^{i}\right)_{i}$ is fixed by the regulators. It should be natural to choose this lower bound by observing the average values of $\left(\mathcal{I}^{i}\right)_{i}$ when there is no financial crisis.

Definition 2.13 Let $\mathcal{I}^{*} \geq 0$ be a uniform lower threshold for $\left(\mathcal{I}^{i}\right)_{i}$ imposed by the regulators. The minimal capital adequacy ratio is defined by $\Re_{t}^{* i}=\left(E_{t-1}^{i} / A_{t-1}^{i}\right) \geq 0$ such that $T-T^{*} \geq \mathcal{I}^{*}$ i.e.

$$
\Re_{t}^{* i}:=\max \left(\frac{\frac{\left(1+R_{i, t}^{D}\right) \mathcal{I}^{*}}{T_{t}^{i}}-\left(R_{i, t}^{A, d}-R_{i, t}^{D}\right)}{\alpha+R_{i, t}^{D}} ; 0\right) .
$$

When $\mathcal{I}^{*}$ is given, we denote $\Re_{t}^{* i}$ by $\Re_{t}^{* \mathcal{I}^{*}, i}$. Observe that $\Re_{t}^{* \mathcal{I}^{*}, i}=0$ means that $\mathcal{I}^{i} \geq \mathcal{I}^{*}$ whatever the positive value of $E_{t-1}^{i} / A_{t-1}^{i}$.

\footnotetext{
${ }^{4}$ Indeed, $R_{i, t}^{A} \leq-1$ corresponds to a significant value depreciation that is not considered in the dynamics of $I$ but in the rate $T_{t}^{i}=0$.
} 
Remark 2.14 We may define rigorously $\Re_{t}^{* i}$ as the $\mathcal{F}_{t-1}^{i}$-measurable random variable

$$
\Re_{t}^{* i}:=\mathcal{F}_{t-1}^{i}-\operatorname{esssup}\left(\frac{\frac{\left(1+R_{i, t}^{D}\right) \mathcal{I}^{*}}{T_{t}^{i}}-\left(R_{i, t}^{A, d}-R_{i, t}^{D}\right)}{\alpha+R_{i, t}^{D}} ; 0\right),
$$

where $\mathcal{F}_{t-1}^{i}$ - esssup designates the $\mathcal{F}_{t-1}^{i}$-measurable essential supremum of any family of random variables. We refer the reader to Kabanov and Lépinette (2012) for a generalization of the usual notion of an essential supremum. At time $t-1, \Re_{t}^{* i}$ turns out to be a constant hence, $\Re_{t}^{* i}$ is a vraimax i.e. the smallest constant dominating the random variable in the r.h.s. of Formula (2.18).

\subsection{Banking Sector Regulation}

This section is concerned with the regulation of the banking system as a whole. To do so, we introduce the following systemic-wide risk indicator of the system defined as

$$
T_{t}^{*}:=\sum_{i=1}^{N_{t-1}} \gamma_{t-1}^{i} T_{t}^{* i}
$$

This indicator is computed as the weighted sum of the indicators $T_{t}^{* i}$ hence financial stability occurs when $T_{t}^{*}$ is not too large. This indicator might be a useful indicator for tracking a possible financial crisis. The higher $T_{t}^{*}$ is, the more fragile the economy should be. Notice that $T_{t}^{* i}$ is computed at the bank-specific level and transmitted to the regulator. Each bank $i$ ignores the indicators $\left(T_{t}^{* j}\right)_{j \neq i}$ of the other banks. By contrast, the regulator observes all of them.

Notice that our model exhibits a contagion phenomenon that we observe through the following asset recovery rates:

$$
X_{t}^{i}=1_{0<E_{t-2}^{i} / A_{t-2}^{i} \leq \Re_{t-1}^{i}} \sum_{k=m}^{10}\left(1-h^{i}\left(\alpha^{k}\right)\right) 1_{\alpha_{k+1} \geq\left|\Delta E_{t-1}^{i}\right| / E_{t-2}^{i} \geq \alpha_{k}}+1_{E_{t-2}^{i} / A_{t-2}^{i}>\Re_{t-1}^{i}} .
$$

The conditional probability that bank $i$ fails at time $t$ is given by

$$
P_{t-1}^{i}\left(X_{t+1}^{i} \neq 1\right)=P_{t-1}\left(R_{i, t}^{A} \leq \frac{1}{T_{t}^{i}}\left[1+R_{i, t}^{D}-\frac{E_{t-1}^{i}}{A_{t-1}^{i}}\left(\alpha+R_{i, t}^{D}\right)\right]-1\right)
$$

where $P_{t-1}^{i}(A):=P\left(A \mid \mathcal{F}_{t-1}^{i}\right)$ is the conditional probability measure. We recall that at time $t-1, X_{t+1}^{i}$ is random for the whole system; however $X_{t+1}^{i}$ is known (deterministic) at time $t$ by bank $i$, i.e. $X_{t+1}^{i} \in$ $L^{0}\left(\mathbf{R}, \mathcal{F}_{t}^{i}\right)$, while it remains a random variable for the other banks because we only have by assumption $X_{t+1}^{i} \in L^{0}\left(\mathbf{R}, \mathcal{F}_{t+1}^{j}\right)$ for all $j$.

Observe that if $T_{t}^{i}$ tends to 0 , the probability that the bank $i$ fails converges to 1 . With $T_{t}^{i}=1$, default happens if the investment return $R_{i, t}^{A}$ is too small. Notice that the contagion phenomenon may occur through the bank-specific recovery rates $T_{t}^{i}$ because they impact the next rates $T_{t+1}^{j}, j \neq i$, through the recovery rates $X_{t+1}^{i}$ of the risky assets issued by bank $i$. Recall that the large depreciations are captured by the recovery rates $T_{t}^{i}$ according to the definition of our model, while $R_{i, t}^{A}$ does not include defaults. This 
fact means that according to our model, contagion is essentially transmitted by the rates $\left(T_{t}^{i}\right)_{i}$. Therefore, it is pertinent for the regulator to monitor the rates $\left(T_{t}^{i}\right)_{i}$.

Because the regulator is concerned with social welfare, it is legitimate to care about the economic growth rate $\mathrm{G}(t)$ of the system:

$$
\mathrm{G}(t):=\sum_{i} \gamma_{t-1}^{i} \frac{A_{t-1}^{i}\left(1+R_{i, t}^{A}\right) T_{t}^{i}-A_{t-1}^{i}}{A_{t-1}^{i}}=\sum_{i} \gamma_{t-1}^{i} R_{i, t}^{A d},
$$

where

$$
\gamma_{t}^{i}:=\frac{A_{t}^{i}}{\sum_{j} A_{t}^{j}} \in L^{0}\left(\mathbf{R}, \mathcal{F}_{t}\right)
$$

It is easily seen that the growth rate is impacted by the default rates of the system. In particular, if we assume that the bond price $S_{i}^{D}=S_{j}^{D}=S^{D}$ models the instantaneous borrowing rate for all $i, j$, then using the notation $\tilde{X}_{t}=X_{t} / S_{t}^{D}$ for discounted processes, we obtain that

$$
\widetilde{\mathrm{G}}(t):=\sum_{i} \gamma_{t-1}^{i} \frac{A_{t-1}^{i}\left(1+\Delta \tilde{I}_{t}^{i} / \tilde{I}_{t-1}^{i}\right) T_{t}^{i}-A_{t-1}^{i}}{A_{t-1}^{i}} .
$$

Assume that there is a martingale probability measure $Q \sim P$ for the prices $\left(\tilde{I}^{i}\right)_{i}$ under no arbitrage conditions of the system. Because we suppose that the random variables $X_{t}^{i}$ are $\mathcal{F}_{t-1}^{i}$ measurable, hence, $\mathcal{F}_{t-1}$ measurable, we deduce that the random variables $T_{t}^{i}$ are also $\mathcal{F}_{t-1}$ measurable. Therefore, $E_{Q}\left(\widetilde{\mathrm{G}}(t) \mid \mathcal{F}_{t-1}\right)=T_{t}-1$ where

$$
T_{t}:=\sum_{i} \gamma_{t-1}^{i} T_{t}^{i} \in[0,1]
$$

is the banking sytem recovery rate weighted by the bank sizes. This rate represents the recovery rate at the system level. Therefore, this is a motivation for the regulator to control the indicator $T_{t}$ by maximizing as much as possible each contribution $\gamma_{t-1}^{i} T_{t}^{i}{ }^{5}$.

Remark 2.15 Notice that we may also observe the contagion phenomenon through $T_{t}$ because the recovery rates $\left(T_{t-1}^{i}\right)_{i}$ impact the recovery rates $\left(T_{t}^{i}\right)_{i}$ and so does the average recovery rate $T_{t}$. As we have already suggested in Remark 2.7, the regulator might impose for each bank $i$ that $P_{t-1}\left(T_{t}^{i} \geq T_{t}^{* i}\right) \geq 1-\epsilon_{t-1}$ for some $\epsilon_{t-1}>0$ because $T_{t}^{i} \geq T_{t}^{* i}$ implies that $X_{t+1}^{i}=1$, i.e., this condition avoids failure of the bank $i$ at time $t$ and thus the contagion of possible failures with probability $1-\epsilon_{t-1}$ from bank $i$ to other elements of the system at the next instant $t+1$.

We propose that the regulator choose thresholds $c_{t-1}^{i} \leq \gamma_{t-1}^{i} T_{t}^{i}$, where $c_{t-1}^{i} \in L^{0}\left(\mathbf{R}_{+}, \mathcal{F}_{t-1}^{i}\right)$. These thresholds can be interpreted as minimal bank specific contributions to the average recovery rate of the system $T_{t}$. By imposing the inequality $P_{t-1}\left(\gamma_{t-1}^{i} T_{t}^{i} \geq c_{t-1}^{i}\right) \geq 1-\epsilon_{t-1}$, where $\epsilon_{t-1} \in L^{0}\left((0, \infty), \mathcal{F}_{t-1}\right)$, we obtain that $T_{t}:=\sum_{i} \gamma_{t-1}^{i} T_{t}^{i} \geq \sum_{i} c_{t-1}^{i} \geq c_{t-1}$ with probability $1-\epsilon_{t-1}^{0}$ for some $\epsilon_{t-1}^{0}$ to be chosen by the regulator. Here, $c_{t-1} \in L^{0}\left(\mathbf{R}_{+}, \mathcal{F}_{t-1}\right)$ is a threshold for the banking system recovery rate $T_{t}$ fixed at time $t-1$ by the regulator.

${ }^{5}$ Discussing of the relevance of such an assumption of absence of arbitrage opportunities for the whole system defined by the fictitious prices $\left(\tilde{I}^{i}\right)_{i}$ is beyond of our scope. 
We suggest to choose $c_{t-1}^{i}$ as a function of $\gamma_{t-1}^{i}$, i.e. $c_{t-1}^{i}=f\left(\gamma_{t-1}^{i}\right)$ where $f$ is a positive and nondecreasing function on $[0,1]$ such that $f(x) \leq x$ and $f(0)=0, f(1)=1$. Moreover, we require that such a function must satisfy the inequality

$$
\sum_{i} f\left(\gamma_{t-1}^{i}\right)=\sum_{i} c_{t-1}^{i} \geq c_{t-1}
$$

For the sake of regulating both the whole banking system (regarding the recovery rate of the system) and each bank (regarding failures), a simple idea is to require that

$$
T_{t}^{i} \geq f\left(\gamma_{t-1}^{i}\right) / \gamma_{t-1}^{i} \vee T_{t}^{* i}
$$

with probability greater than $1-\epsilon_{t-1}$ because it should avoid both contagion of failures $\left(T_{t}^{i} \geq T_{t}^{* i}\right)$ and a negative impact on the recovery rate $\left(T_{t}^{i} \geq f\left(\gamma_{t-1}^{i}\right) / \gamma_{t-1}^{i}\right.$ or $\left.T_{t}^{i} \gamma_{t-1}^{i} \geq c_{t-1}^{i}\right)$ of the system.

If we assume that the random variables $\left(T_{t}^{i}, T_{t}^{* i}\right)_{i}$ are conditionally independent with respect to $\mathcal{F}_{t-1}$ ${ }^{6}$, it suffices to choose $\epsilon_{t-1}$ such that $\left(1-\epsilon_{t-1}\right)^{N_{t-1}}:=1-\epsilon_{t-1}^{0}$ where $N_{t-1}$ is the predictable number of banks at time $t-1$. Precisely, we obtain that

$$
\epsilon_{t-1}:=1-\left(1-\epsilon_{t-1}^{0}\right)^{1 / N_{t-1}}
$$

and observe that $\epsilon_{t-1} \leq \epsilon_{t-1}^{0}$. Under such requirements (i.e. Inequality 2.24 holds for all $i$ ), we obtain, with a probability greater than $1-\epsilon_{t-1}^{0}$, that $T_{t} \geq c_{t-1}$ and no bank fails.

Remark 2.16 Let us suggest a possible funtion $f$. Recall that $f$ is an increasing and positive function on $[0,1]$ such that $f(0)=0$ and $f(1)=1$. Consider the convex function $f(x)=x^{m}$ on $[0,1]$ where $m \geq 1$ to be defined. We have

$$
\sum_{i} c_{t-1}^{i}=\sum_{i} f\left(\gamma_{t-1}^{i}\right) \geq c_{t-1} \Leftrightarrow \sum_{i} \frac{1}{N_{t-1}} f\left(\gamma_{t-1}^{i}\right) \geq \frac{c_{t-1}}{N_{t-1}}
$$

and by Jensen's inequality, because $f$ is convex, we deduce that

$$
\sum_{i} \frac{1}{N_{t-1}} f\left(\gamma_{t-1}^{i}\right) \geq f\left(\frac{1}{N_{t-1}}\right)
$$

Then, for $(2.26)$ to be satisfied, it is sufficient that $f\left(\frac{1}{N_{t-1}}\right)=\frac{c_{t-1}}{N_{t-1}}$. We then deduce that

$$
m=m_{t-1}:=\frac{-\log \left(c_{t-1}\right)}{\log \left(N_{t-1}\right)}+1
$$

where $N$ is supposed to be predictable, i.e. $N_{t-1} \in L^{0}\left(\mathbf{R}_{+}, \mathcal{F}_{t-2}\right)$. Choosing also $c \in[0,1)$ as a predictable process, this means that $m_{t-1}$ is known at time $t-2$ by the whole system. Observe that if $c$ is a constant process, then $m_{t-1}$ is closed to one as $N_{t-1} \rightarrow \infty$ but remains strictly greater than one. Therefore, $f$ depends on time and is defined by

$$
f(x)=f_{t-1}(x)=x^{m_{t-1}}=x^{\frac{-\log \left(c_{t-1}\right)}{\log \left(N_{t-1}\right)}+1} .
$$

The minimal bank specific contributions are given by $c_{t-1}^{i}=\left(\gamma_{t-1}^{i}\right)^{m_{t-1}}$.

6 This idealistic situation is based on the intuition that the levels of risk given by $\left(T_{t}^{i}, T_{t}^{* i}\right)_{i}$ are chosen independently at time $t-1$ by the choices of the bank specific strategies. Observe that we do not suppose that each $T_{t}^{i}$ is independent of the rates $\left(T_{s-1}^{j}\right)_{j}, s \leq t$ because it would contradict the contagion phenomena. 
In conclusion, we propose that the regulator fix the predictable default probability $\epsilon^{0}$ of the banking system and the predicable threshold process $c$. Therefore, the predictable processes $f$ (or $m$ ) and the uniform bank-specific default $\epsilon$ are defined. This fact means that the regulator requires that each bank $i$ chooses an investment strategy at time $t-1$ such that the distribution of the corresponding random variable $T_{t}^{i}$ satisfies $P_{t-1}\left(T_{t}^{i} \geq f\left(\gamma_{t-1}^{i}\right) / \gamma_{t-1}^{i} \vee T_{t}^{* i}\right) \geq 1-\epsilon_{t-1}$. Notice that when $f(x)=f_{t-1}(x)=x^{m_{t-1}}$, the minimal required bank-specific recovery rate $f\left(\gamma_{t-1}^{i}\right) / \gamma_{t-1}^{i}$ is given by

$$
f\left(\gamma_{t-1}^{i}\right) / \gamma_{t-1}^{i}=\left(\gamma_{t-1}^{i}\right)^{\frac{-\log \left(c_{t-1}\right)}{\log \left(N_{t-1}\right)}}=e^{\frac{-\log \left(c_{t-1}\right) \log \left(\gamma_{t-1}^{i}\right)}{\log \left(N_{t-1}\right)}}
$$

Notice that the regulator should be able to detect the black sheeps of the banking system i.e. the banks $i$ such that $\gamma_{t-1}^{i} T_{t}^{i} \leq f\left(\gamma_{t-1}^{i}\right)$.

\section{Descriptive Statistics}

The database includes the major banks from the G5: USA, Japan, Germany, France and UK. The data spans 6 years from 2005 to 2012 for most of the banks: Table 1 displays the average values of the data set per year while Table 2 exposes the same variables by banks.

Nineteen major banks are selected according to their rank:

- France (4): BnpParibas, Societe Generale, Credit Agricole, Natixis.

- Japan (3): Mitsubishi UFJ Financial Group Inc, Mizuho Financial Group, Resona Holdings.

- Germany (3): Deutsche Bank, Commerzbank, Hypo Real Estate Holding.

- UK (4): HSBC Holdings Plc, Royal Bank of Scotland Group Plc, Lloyds Banking Group Plc, Barclays Bank Plc.

- USA (5): JP Morgan Chase \& Co., Bank of America Corporation, Citigroup Inc, Wells Fargo \& Company, Goldman Sachs Group.

The balancesheet data used to implement the regulator model are as follows:

- Total Assets (A) corresponds to the total amount of assets.

- Total Liabilities (D) corresponds to the total amount of outstanding debt.

- Equity (E) corresponds to the total amount of equity.

- Total dividends paid and declared in the given period $(\Delta C)$.

- Return on average assets (ROAA) corresponds to the return on investment.

- Return on average equity $\left(R^{E}\right)$ corresponds to the return on equity.

- Interest Expense/ Average Interest-bearing Liabilities $\left(R^{D}\right)$ corresponds to the average cost of debt.

Market data that are extracted from Datastream:

- Ten-year government yield $\left(R^{0}\right)$ represents risk-free interest rate.

- Stock index return $\left(R^{M}\right)$ corresponds to the average return of the main stock indexes (Dow Jones, CAC 40, DAX 30, FTSE 100 and Nikkei 225)

\section{Empirical Findings}


In the following, we present the results of our data analysis. We fix $\alpha=10 \%$ as a reasonable threshold given our sample. In practice, each bank has its own modeling of the return $R^{A}$. Because this information is confidential, we have no choice but fixing a common dynamic for all banks. Precisely, we assume that $R^{A}$ is given by (2.4). For the sake of simplicity, we choose $h^{i}(x)=x$ for all $i$.

We implement the model by computing the fragility rate $T_{t}^{* i}$ for each bank $i$ given by Formula (2.15). We deduce the system-wide fragility rate $T_{t}^{*}$ at the country level and then at the international level. Similarly, we compute the corresponding recovery rate $T_{t}$ at each level using Formula (2.7). From there, we compute the capital-ratio threshold $\Re$ given by Formula (2.14) at each level as well as the capital ratio threshold $\Re^{* \mathcal{I}^{*}}$ given by Formula (2.18) where we make our choice $\mathcal{I}^{*}=1.3$ in accordance with the system-wide immunity level of 2006 (see Figure 7). We finally deduce the immunity level $\mathcal{I}$. It is worth noticing that the recovery rate $T^{i}$ of bank $i$ is initially defined by the expression given in Formula (2.12); however, the information to compute the recovery rate is not available. This fact explains why the observed values of $T^{i}$ given by Formula (2.7) may lie outside the interval $[0,1]$. Nevertheless, this approximation provides satisfying results.

Table 3 displays the system-wide fragility rate $T^{*}$ at the international level. As observed in Figure 1, this rate continuously increases from 2005 until 2008 with an alarming level in 2007. This increase means that the system was getting more and more fragile. The high level of $T^{*}$ in 2007 turns out to be consistent with the financial crisis of 2008 and appears to be a good leading indicator. The next crisis of 2011 in the European area appears to be anticipated by $T^{*}$. We observe the same leading behavior for every country except Germany (see Figure 2). Recall that our modeling choice for $R^{A}$ is subject to a lack of information leading us to choose a common dynamic. We may deduce either that the indicator $T^{*}$ does not fit the German case or that the German banking sector does not behave as the others. In particular, the fragility of Germany given by $T^{*}$ has been delayed in 2009 contrarily to the other countries impacted in 2008. This finding leads to looking for specific indicators $T^{*}$ for each country by choosing appropriate dynamics for $R^{A}{ }^{7}$. Note that the behavior of $T^{*}$ is very similar for each bank of the same country as illustrated for the USA in Figure 4; however, this behavior is also observed in the other countries. Actually, each country's indicator $T^{*}$ has its own feature as shown in Figure 5 .

Figure 6 shows the capital-ratio threshold $\Re$ of each bank of the USA. This threshold provides the same type of information than the indicator $T^{*}$, i.e., it measures the fragility of the bank; however, notice that the values are more dispersed. Hence, this threshold allows to better discriminate the fragilities of the banks but is apparently not a leading indicator. As observed, CityGroup and Bank of America are more fragile, which is consistent with what has been observed in the American case ${ }^{8}$.

The immunity level is not a leading factor but reflects well the resistance of the banks and more generally of the system. In particular, Figure 7 shows that this immunity decreased from 2006 to 2009. After the turmoil of 2008, the banks increased their immunity as expected. The ranking of each bank is given in Table 4, where the U.S. banks appear the most resistant while the German ones are the least resistant according to the immunity measure $\mathcal{I}$. The international portfolio market in Figure 8 is computed as the weighted average between the country portfolio markets and is normalized by a constant multiplier such that its initial value equals the value of $\mathcal{I}$ in 2005. It is well explained as a function of the immunity level $T-T^{*}$ through a linear approximation. As expected, the larger the immunity level, the largerthe portfolio market. This result confirms the relevance of the indicator $\Re^{*}$ even whether this relevance needs to be confirmed for a longer period of observation.

\footnotetext{
7 In the case of Germany, the rule of thumb $R^{A}=R^{D}+R O O A$ provides a better anticipation of the financial crisis of 2008 and 2011, as illustrated in Figure 3. However, the selection of specific indicators is beyond our scope and left for future research.

8 According to the Bloomberg source on bank losses available upon request.
} 
Figure 9 exposes the capital adequacy ratio threshold $\Re^{*}:=\Re^{* 1.3 \%}$ at the country and international levels where $\mathcal{I}^{*}=1.3 \%$ is a value above which the system-wide indicator $\mathcal{I}$ was in 2006 . Recall that $\Re_{t}^{* 1.3 \%}=0$ means that the inequality $T-T^{*} \geq 1.3 \%$ holds whatever the ratio $E / A$ is at time $t-1$. A deeper data analysis for a longer period of time may help the regulators to determine a relevant threshold $\mathcal{I}^{*}$ defining $\Re^{*}:=\Re^{* \mathcal{I}^{*}}$ to avoid a major financial crisis. For instance, Table 5 presents $\Re^{* 1.3 \%}$ for each bank. Clearly, $\Re^{* 1.3 \%}$ vary in time, which is intuitively natural because it also depends on the context specific to each bank. Therefore, a uniform capital adequacy ratio imposed by the regulators appears not to be sufficient to avoid a major financial crisis. Following the evolution of the capital ratio $E / A$, as illustrated in Figure 10, we might think that the decline of $E / A$ in 2007 explains (or accompanies) the financial crisis of 2008. However, note that this ratio was in 2007 at the same level than in 2005. Nevertheless, the Euro-zone crisis occurred in 2011 despite of the substantial rise of the ratio $E / A$. As a consequence, even if a uniform capital ratio requirement for $E / A$ is a lever to reinforce the immunity of each bank against default, it appears not to be sufficient. In particular, the fragility implied by a small capital ratio may be compensated by safer investments that increase the recovery rate $T$. Therefore, fixing a uniform immunity lower bound for $\mathcal{I}$ appears to be more appropriate than a uniform capital ratio $E / A$.

\section{Conclusion}

The regulators current objective is to determine the bank capital ratio allowing to reach international minimum standards lowering systemic risk. However, the Basel framework suffers from various weaknesses. First, the Basel framework asks for uniform minimum levels of capital ratio, which is likely to reduce banks' profitability and lending capacity. Second, the framework remains mainly microprudential oriented; it deals with individual uniform requirements without considering the weight of each bank in the economy.

This paper addresses these issues by deriving a regulation model. This new model combines several attractive features. Instead of considering the uniform Basel capital ratio as the systemic risk lever, this model characterizes systemic risk in terms of recovery rates. It monitors the systemic risk requirements both at the bank and at the system level. Finally, this easy-to-implement model captures dynamically the contagion phenomenon.

We test the adequacy of the model on a data set containing 19 banks of 5 major countries from 2005 to 2012. The results confirm the relevance of three main indicators derived from the model. The fragility indicator $T^{*}$ turns out to be a leading indicator for financial crises while the immunity indicator $T-T^{*}$ indicates the resilience of each bank. The capital ratio threshold indicator $\Re^{*}$ is adopted from a uniform lower bound for the immunity level $T-T^{*}$ instead of a uniform lower bound for the capital ratio $E / A$.

A future research may consider an optimal criterion to derive an immunity level threshold requirement for $\mathcal{I}$ that maximizes bank profitability without harming common welfare. In addition, we leave for the future the study of the contagion phenomenon given by Formula (2.20) and an empirical study based on a longer period.

\section{Appendix}

6.1 Tables 


\section{Table 1 Descriptive statistics per year}

Table 1 exposes the arithmetic average values, per bank, of the variables used in the model. Five countries are represented: France, Germany, Japan, the UK and the US. The period considered goes from 2004 to 2012. The table displays the total assets $(A)$, the total liabilities $(D)$, the total equity $(E)$, the ratio of interest expense on the average interest-bearing liabilities as a proxy of the cost of the debt $\left(R_{D}\right)$, the return on the average equity as a proxy of the cost of equity $\left(R_{E}\right)$, the total dividends paid and declared in the given period (Dividends) and the size of the bank relative to its country $\left(\gamma_{i}\right)$. The variable are expressed in millions of local currency for the variables $(A),(E)$, $(D)$ and $(\Delta C)$. Note that the negative average cost of equity $R^{E}$ for Germany is due to the bankruptcy of Hypo Real Estate Holding AG. The exclusion of this bank from the sample gives $R^{E}=6.00 \%$.

\begin{tabular}{|c|c|c|c|c|c|c|c|c|c|}
\hline$U S$ & Average & 2012 & 2011 & 2010 & 2009 & 2008 & 2007 & 2006 & 2005 \\
\hline Asset $(A)$ & 1511175.40 & 1759059.60 & 1701161.60 & 1693175.20 & 1640904.40 & 1625130.20 & 1432152.40 & 1203154.40 & 1034665.40 \\
\hline Debt $(D)$ & 1369964.88 & 1578932.20 & 1527521.60 & 1521994.60 & 1476736.20 & 1477510.00 & 1323230.00 & 1103964.20 & 949830.20 \\
\hline Equity $(E)$ & 129279.08 & 173329.80 & 161062.60 & 155077.60 & 147646.20 & 130778.80 & 96263.00 & 91453.20 & 78621.40 \\
\hline Cost of debt $\left(R^{D}\right)$ & $1.99 \%$ & $0.92 \%$ & $1.06 \%$ & $1.09 \%$ & $1.35 \%$ & $2.30 \%$ & $3.50 \%$ & $3.33 \%$ & $2.39 \%$ \\
\hline Cost of equity $\left(R^{E}\right)$ & $9.84 \%$ & $8.02 \%$ & $7.14 \%$ & $7.53 \%$ & $7.53 \%$ & $-1.62 \%$ & $13.93 \%$ & $19.11 \%$ & \\
\hline Dividends $(\Delta C)$ & 3427.15 & 1994.00 & 1566.00 & 617.40 & 826.20 & 5378.60 & 6237.60 & 5700.40 & 5097.00 \\
\hline $\begin{array}{l}\text { Risk free rate }\left(R_{0}\right) \\
\text { Portfolio market return }\left(R_{M}\right)\end{array}$ & $\begin{array}{l}2.52 \% \\
2.02 \%\end{array}$ & & & & & & & & \\
\hline$U K$ & Average & 2012 & 2011 & 2010 & 2009 & 2008 & 2007 & 2006 & 2005 \\
\hline Asset $(A)$ & 1402104.32 & 1702612.33 & 1630577.00 & 1560907.75 & 1525959.00 & 1723614.25 & 1262715.75 & 1012271.50 & 873304.00 \\
\hline Debt $(D)$ & 13337 & 16026 & 1543356.50 & 1478017.00 & 14495 & 1671372.25 & 1203277.75 & .75 & 25 \\
\hline Equity $(E)$ & 66270.35 & 96902.33 & 84927.75 & 80516.25 & 73666.00 & 50188.00 & 56874.25 & 50483.75 & 44262.50 \\
\hline Cost of debt $\left(R^{D}\right)$ & $1.72 \%$ & $1.36 \%$ & $0.96 \%$ & $0.99 \%$ & $1.23 \%$ & $1.94 \%$ & $2.57 \%$ & $2.44 \%$ & $2.13 \%$ \\
\hline Cost of equity $\left(R^{E}\right)$ & $9.84 \%$ & $1.75 \%$ & $2.26 \%$ & $3.79 \%$ & $9.45 \%$ & $2.19 \%$ & $19.42 \%$ & $19.37 \%$ & $18.45 \%$ \\
\hline & 3358.43 & 3276.00 & 2679.00 & 2110.00 & 1868.25 & 4580.25 & 5131.67 & 3780.50 & 3382.50 \\
\hline Risk free rate $\left(R_{0}\right)$ & $2.71 \%$ & & & & & & & & \\
\hline Portfolio market return $\left(R_{M}\right)$ & $\begin{array}{l}1.95 \% \\
\text { Average }\end{array}$ & 2012 & 2011 & 0 & 2009 & 2008 & 2007 & 2006 & 2005 \\
\hline Asset $(A)$ & 126 & 0 & 97 & & & & & & 120869.10 \\
\hline & & & 53 & & & & & & 113627.37 \\
\hline$(E)$ & $\begin{array}{l}118169 . \\
5956 .\end{array}$ & 6796.03 & 6342.77 & 6469.47 & $\begin{array}{l}118282.13 \\
4978.40\end{array}$ & 5939.57 & 6406.07 & 5934.80 & 4784.67 \\
\hline Cost of debt $\left(R^{D}\right)$ & $0.53 \%$ & $0.22 \%$ & $0.24 \%$ & $0.31 \%$ & $0.71 \%$ & $1.05 \%$ & $0.85 \%$ & $0.52 \%$ & $0.32 \%$ \\
\hline Cost of equity $\left(R^{E}\right)$ & $9.95 \%$ & $10.97 \%$ & 6.90 & 5.7 & $-2.68 \%$ & $8.81 \%$ & $18.81 \%$ & $17.22 \%$ & $13.79 \%$ \\
\hline Dividends $(\Delta C)$ & 82.58 & 114.47 & 109.97 & 96.73 & 85.07 & 90.40 & 68.90 & 39.33 & 42.35 \\
\hline Risk free rate $\left(R_{0}\right)$ & $0.96 \%$ & & & & & & & & \\
\hline Portfolio market return $\left(R_{M}\right)$ & $-0.68 \%$ & & & & & & & & \\
\hline Germany & Average & 2012 & 2011 & 2010 & 2009 & 2008 & 2007 & 2006 & \begin{tabular}{|l|}
2005 \\
29860000
\end{tabular} \\
\hline Asset $(A)$ & $8 !$ & N.A. & 1020 & 996016.00 & 901481.00 & 1082433.67 & .33 & .67 & $\begin{array}{l}298600.00 \\
81176.00\end{array}$ \\
\hline Debt $(D)$ & 86879 & N.A. & 1021 & 127 & 134064.33 & 1541 & & 686 & \\
\hline Equity $(E)$ & 21113.10 & N.A. & 27285.00 & 27348.33 & 22845.00 & 17362.00 & 16909.00 & 14160.33 & 7554.00 \\
\hline Cost of debt $\left(R^{D}\right)$ & $2.71 \%$ & N.A. & $2.08 \%$ & $2.28 \%$ & $2.85 \%$ & $3.89 \%$ & $4.36 \%$ & $4.51 \%$ & $4.68 \%$ \\
\hline Cost of equity $\left(R^{E}\right)$ & $-13.93 \%$ & N.A. & $2.56 \%$ & $-14.72 \%$ & $-144.21 \%$ & $-239.20 \%$ & $9.60 \%$ & $16.62 \%$ & $12.77 \%$ \\
\hline Divid & 452 & N.A. & 0.0 & 0.0 & 0.0 & 0.0 & 101.00 & 201.00 & 134.00 \\
\hline Risk free rate & 2.27 & & & & & & & & \\
\hline Portfolio market re & & & & & & & & & \\
\hline France & & 201 & & & & & & & \\
\hline Ass & 12 & & & & & & & & \\
\hline $\operatorname{Debt}(D)$ & 1177 & 11726 & $13225 ?$ & 1268728.75 & 1248161.00 & & 1160511.50 & 1015507.75 & 892722.00 \\
\hline Equity $(E)$ & 50306.83 & 56173.00 & 58670.25 & 58851.00 & 55822.75 & 46285.75 & 44574.75 & 42311.25 & 38207.67 \\
\hline Cost of debt $\left(R^{D}\right)$ & $2.40 \%$ & $1.46 \%$ & $1.58 \%$ & $1.37 \%$ & $1.62 \%$ & $3.09 \%$ & $3.73 \%$ & $3.44 \%$ & $2.81 \%$ \\
\hline Cost of equity $\left(R^{E}\right)$ & $7.09 \%$ & 5.0 & & & & & & & \\
\hline Dividends $(\triangle C)$ & 1226.70 & N. & 1330.33 & 1308.00 & 1239.67 & 804.38 & 999.50 & 1715.05 & 1800.00 \\
\hline Portfolio market return $\left(R_{M}\right)$ & $\begin{array}{l}2.50 \% \\
-0.51 \%\end{array}$ & & & & & & & & \\
\hline
\end{tabular}

Table 2 Descriptive statistics per bank

Table 2 exposes the average values, per bank, of the variables used in the model. Five countries are represented: France, Germany, Japan, the UK and the US. The period considered goes from 2004 to 2012. The table displays the total assets $(A)$, the total liabilities $(D)$, the total equity $(E)$, the ratio of interest expense on the average interest-bearing liabilities as a proxy of the cost of the debt $\left(R_{D}\right)$, the return on the average equity as a proxy of the cost of equity $\left(R_{E}\right)$, the total dividends paid and declared in the given period $(\Delta C)$ and the size of the bank relative to its country $\left(\gamma_{i}\right)$. The variable are expressed in millions of local currency for the variables $(A),(E),(D)$ and $(\Delta C)$.

\begin{tabular}{|c|c|c|c|c|c|}
\hline US & JP Morgan & BoA & Citigroup & Wells Fargo & Goldman Sachs \\
\hline Asset $(A)$ & 1882773.50 & 1889057.13 & 1876692.75 & 1010928.38 & 896425.25 \\
\hline Debt $(D)$ & 1711410.38 & 1685067.50 & 1713357.50 & 903979.88 & 836009.13 \\
\hline Equity $(E)$ & 155277.38 & 185926.13 & 147360.00 & 97415.75 & 60416.13 \\
\hline Cost of debt $\left(R^{D}\right)$ & $2.15 \%$ & $2.49 \%$ & $2.72 \%$ & $2.00 \%$ & $0.61 \%$ \\
\hline Cost of equity $\left(R^{E}\right)$ & $9.55 \%$ & $6.48 \%$ & $4.82 \%$ & $13.37 \%$ & $14.98 \%$ \\
\hline Dividends $(\Delta C)$ & 3861.13 & 4979.63 & 4490.88 & 3206.00 & 598.13 \\
\hline Size $\left(\gamma_{i}\right)$ & $23.83 \%$ & $25.97 \%$ & $26.58 \%$ & $13.27 \%$ & $12.66 \%$ \\
\hline UK & $\mathrm{HSBC}$ & Royal Bank of Scotland & Lloyds & Barclays & \\
\hline Asset $(A)$ & 2288964.63 & 1238891.29 & 669582.25 & 1390577.50 & \\
\hline Debt $(D)$ & 2143335.88 & 1189792.86 & 640297.13 & 1343559.00 & \\
\hline Equity $(E)$ & 138499.50 & 49098.43 & 28318.50 & 47018.50 & \\
\hline Cost of debt $\left(R^{D}\right)$ & $1.72 \%$ & $1.26 \%$ & $2.72 \%$ & $1.04 \%$ & \\
\hline Cost of equity $\left(R^{E}\right)$ & $10.81 \%$ & $3.71 \%$ & $11.08 \%$ & $12.98 \%$ & \\
\hline Dividends $(\Delta C)$ & 8189.50 & 2599.50 & 992.25 & 1273.00 & \\
\hline Size $\left(\gamma_{i}\right)$ & $42.77 \%$ & $19.59 \%$ & $12.05 \%$ & $25.60 \%$ & \\
\hline Japan & Mitsubishi UFJ Financial Group & Mizuho Financial Group & Resona Holdings Inc & & \\
\hline Asset $(A)$ & 189661.29 & 149774.09 & 39826.95 & & \\
\hline Debt $(D)$ & 175961.43 & 141389.68 & 37156.19 & & \\
\hline Equity $(E)$ & 10019.63 & 5891.36 & 1958.43 & & \\
\hline Cost of debt $\left(R^{D}\right)$ & $0.65 \%$ & $0.68 \%$ & $0.25 \%$ & & \\
\hline Cost of equity $\left(R^{E}\right)$ & $5.67 \%$ & $6.90 \%$ & $17.27 \%$ & & \\
\hline Dividends $(\Delta C)$ & 123.33 & 99.68 & 16.47 & & \\
\hline Size $\left(\gamma_{i}\right)$ & $45.26 \%$ & $35.82 \%$ & $9.53 \%$ & & \\
\hline Germany & Deutsche Bank & Commerzbank & Hypo Real Estate Holding AG & & \\
\hline Asset $(A)$ & 1878265.17 & 650723.29 & 294020.14 & & \\
\hline Debt $(D)$ & 1827726.00 & 627039.86 & 288602.86 & & \\
\hline Equity $(E)$ & 41203.17 & 20710.29 & 4295.86 & & \\
\hline Cost of debt $\left(R^{D}\right)$ & $2.33 \%$ & $2.22 \%$ & $3.52 \%$ & & \\
\hline Cost of equity $\left(R^{E}\right)$ & $9.08 \%$ & $3.35 \%$ & $-50.94 \%$ & & \\
\hline
\end{tabular}


Table 3 Fragility indicator per country

Table 3 exposes the fragility indicator $T^{*}$ from 2005 to 2012 for the whole system and for each country: France, Germany, Japan, the UK and the US.

\begin{tabular}{|l|cccccccc|}
\hline \multicolumn{1}{|c|}{$T^{*}$} & 2012 & 2011 & 2010 & 2009 & 2008 & 2007 & 2006 & 2005 \\
\hline US & 0.9409 & 0.9718 & 0.9233 & 0.8851 & 0.9847 & 0.9748 & 0.8971 & 0.9811 \\
UK & 0.9582 & 0.9922 & 0.9369 & 0.8569 & 0.9864 & 0.9875 & 0.9284 & 0.8759 \\
Japan & 0.8534 & 0.9930 & 0.9971 & 0.8884 & 0.9883 & 0.9884 & 0.9604 & 0.7529 \\
Germany & & 1.0011 & 0.8954 & 0.8656 & 0.9971 & 0.8622 & 0.8652 & 0.8291 \\
France & 0.9020 & 0.9920 & 0.9939 & 0.8668 & 0.9927 & 0.9904 & 0.8919 & 0.8463 \\
System & 0.9232 & 0.9885 & 0.9485 & 0.8710 & 0.9889 & 0.9690 & 0.9095 & 0.8701 \\
\hline
\end{tabular}

Table 4 Immunity rank per bank and year

Table 4 exposes the immunity rank $T-T^{*}$ per bank for the international system and for each year from 2005 to 2012 . The first rank characterizes the highest immunity.

\begin{tabular}{|l|cccccccc|c|}
\hline \multicolumn{1}{|c|}{ Rank } & 2012 & 2011 & 2010 & 2009 & 2008 & 2007 & 2006 & 2005 & Average \\
\hline Wells Fargo & 1 & 1 & 1 & 2 & 1 & 1 & 1 & 1 & 1.1 \\
JP Morgan & 2 & 2 & 3 & 3 & 3 & 3 & 4 & 5 & 3.1 \\
BoA & 6 & 7 & 9 & 4 & 2 & 2 & 2 & 3 & 4.4 \\
Goldman Sachs & 3 & 4 & 2 & 1 & 11 & 6 & 6 & 8 & 5.1 \\
HSBC & 4 & 3 & 5 & 6 & 6 & 7 & 8 & 4 & 5.4 \\
CitiGroup & 5 & 5 & 4 & 7 & 18 & 8 & 3 & 2 & 6.5 \\
Resona Holdings Inc & 8 & 6 & 7 & 5 & 4 & 4 & 9 & 9 & 6.5 \\
BNP Paribas & 9 & 8 & 6 & 8 & 13 & 11 & 14 & 11 & 10.0 \\
Lloyds & 16 & 19 & 16 & 13 & 5 & 5 & 5 & 7 & 10.8 \\
Mitsubishi UFJ Financial Group & 7 & 11 & 11 & 11 & 7 & 13 & 10 & 18 & 11.0 \\
Barclays & 14 & 13 & 12 & 9 & 9 & 10 & 13 & 10 & 11.3 \\
SocieteGenerale & 11 & 9 & 8 & 12 & 12 & 17 & 16 & 16 & 12.6 \\
Royal Bank of Scotland & 15 & 17 & 18 & 15 & 15 & 9 & 7 & 6 & 12,8 \\
Credit Agricole & 13 & 14 & 13 & 10 & 10 & 12 & 11 & 19 & 12.8 \\
Mizuho Financial Group & 10 & 12 & 14 & 18 & 8 & 14 & 15 & 12 & 12.9 \\
Natixis & 12 & 10 & 10 & 17 & 17 & 15 & 12 & 13 & 13.3 \\
Deutsche Bank & & 15 & 17 & 16 & 16 & 16 & 18 & 15 & 16.1 \\
Commerzbank & & 16 & 15 & 19 & 14 & 18 & 17 & 14 & 16.1 \\
HypoRealEstateHoldingAG & & 18 & 19 & 14 & 19 & 19 & 19 & 17 & 17.9 \\
\hline
\end{tabular}


Table 5 Capital ratio threshold per bank

Table 5 exposes the capital ratio threshold values $R^{*}$ from 2005 to 2012 for all banks and all countries.

\begin{tabular}{|l|cccccccc|}
\hline \multicolumn{1}{|c|}{$R^{*}$} & 2012 & 2011 & 2010 & 2009 & 2008 & 2007 & 2006 & 2005 \\
\hline JP Morgan & $3.23 \%$ & $3.24 \%$ & $5.7 \%$ & $8.87 \%$ & $7.23 \%$ & $2.01 \%$ & $2.31 \%$ & $3.88 \%$ \\
BoA & $11.7 \%$ & $12.39 \%$ & $14.51 \%$ & $11.52 \%$ & $6.33 \%$ & $0.74 \%$ & $0.00 \%$ & $0.00 \%$ \\
CitiGroup & $9.75 \%$ & $7.98 \%$ & $8.52 \%$ & $14.32 \%$ & $18.17 \%$ & $6.18 \%$ & $0.00 \%$ & $0.00 \%$ \\
Wells Fargo & $0.00 \%$ & $0.05 \%$ & $4.3 \%$ & $4.62 \%$ & $4.15 \%$ & $4.44 \%$ & $0.00 \%$ & $5.13 \%$ \\
Goldman Sachs & $6.02 \%$ & $7.45 \%$ & $4.00 \%$ & $1.87 \%$ & $10.51 \%$ & $0.36 \%$ & $1.92 \%$ & $3.92 \%$ \\
USA & $6.52 \%$ & $6.54 \%$ & $8.31 \%$ & $9.45 \%$ & $9.5 \%$ & $2.56 \%$ & $0.76 \%$ & $1.27 \%$ \\
\hline HSBC & $5.34 \%$ & $4.15 \%$ & $6.39 \%$ & $9.34 \%$ & $7.28 \%$ & $6.5 \%$ & $6.25 \%$ & $0.42 \%$ \\
Royal Bank of Scotland & $13.93 \%$ & $13.67 \%$ & $14.00 \%$ & $13.26 \%$ & $15.96 \%$ & $5.53 \%$ & $3.7 \%$ & $3.3 \%$ \\
Lloyds & $13.35 \%$ & $14.32 \%$ & $12.57 \%$ & $10.73 \%$ & $4.69 \%$ & $0.00 \%$ & $0.90 \%$ & $1.55 \%$ \\
Barclays & $12.94 \%$ & $9.7 \%$ & $10.15 \%$ & $10.58 \%$ & $8.02 \%$ & $4.91 \%$ & $6.24 \%$ & $7.47 \%$ \\
UK & $10.05 \%$ & $9.09 \%$ & $9.86 \%$ & $10.71 \%$ & $9.70 \%$ & $5.44 \%$ & $5.26 \%$ & $3.01 \%$ \\
\hline Mitsubishi UFJ Financial Group & $9.05 \%$ & $9.71 \%$ & $10.05 \%$ & $14.39 \%$ & $8.15 \%$ & $7.33 \%$ & $7.06 \%$ & $17.5 \%$ \\
Mizuho Financial Group & $10.7 \%$ & $0.07 \%$ & $10.12 \%$ & $17.3 \%$ & $9.53 \%$ & $7.76 \%$ & $8.3 \%$ & $11.59 \%$ \\
Resona Holdings Inc & $8.72 \%$ & $7.49 \%$ & $9.3 \%$ & $10.76 \%$ & $6.04 \%$ & $0.00 \%$ & $3.99 \%$ & $5.87 \%$ \\
Japan & $9.65 \%$ & $8.82 \%$ & $9.34 \%$ & $13.76 \%$ & $7.59 \%$ & $5.84 \%$ & $6.28 \%$ & $12.23 \%$ \\
\hline Deutsche Bank & & $9.93 \%$ & $12.24 \%$ & $12.25 \%$ & $12.9 \%$ & $8.04 \%$ & $7.83 \%$ & $09.17 \%$ \\
Commerzank & & $11.09 \%$ & $11.83 \%$ & $19.13 \%$ & $11.06 \%$ & $10.23 \%$ & $8.92 \%$ & $010.84 \%$ \\
Hypo Real Estate Holding AG & & $10.86 \%$ & $13.86 \%$ & $8.04 \%$ & $36.54 \%$ & $9.82 \%$ & $8.31 \%$ & $9.62 \%$ \\
Germany & & $10.25 \%$ & $12.31 \%$ & $13.84 \%$ & $15.6 \%$ & $8.74 \%$ & $8.15 \%$ & $9.05 \%$ \\
\hline BNP Paribas & $9.53 \%$ & $8.48 \%$ & $7.24 \%$ & $10.55 \%$ & $9.18 \%$ & $6.35 \%$ & $7.36 \%$ & $8.68 \%$ \\
Societe Generale & $11.05 \%$ & $8.63 \%$ & $8.2 \%$ & $11.78 \%$ & $8.26 \%$ & $9.12 \%$ & $8.09 \%$ & $11.93 \%$ \\
Credit Agricole & $12.21 \%$ & $11.02 \%$ & $9.55 \%$ & $11.75 \%$ & $9.5 \%$ & $7.15 \%$ & $7.27 \%$ & $33.45 \%$ \\
Natixis & $11.83 \%$ & $9.15 \%$ & $8.74 \%$ & $16.24 \%$ & $15.25 \%$ & $8.99 \%$ & $6.86 \%$ & $9.86 \%$ \\
France & $10.99 \%$ & $9.43 \%$ & $8.33 \%$ & $11.67 \%$ & $9.7 \%$ & $7.5 \%$ & $7.44 \%$ & $17.22 \%$ \\
\hline
\end{tabular}

6.2 Figures

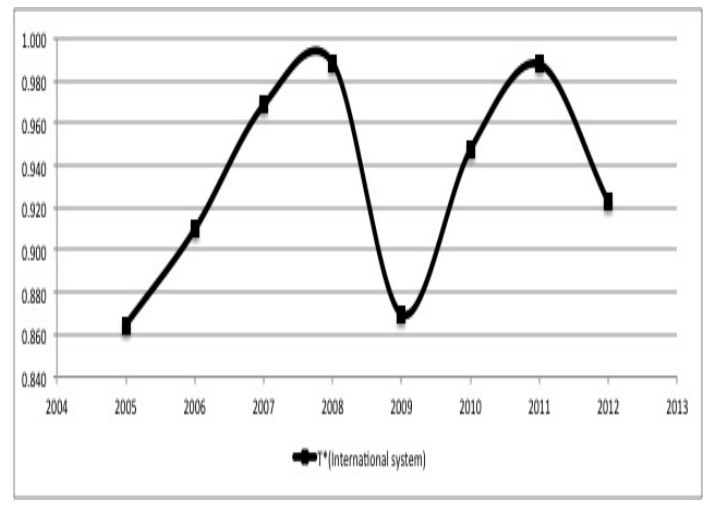

Fig. 1 Fragility indicator $T^{*}$ per year for the international system.

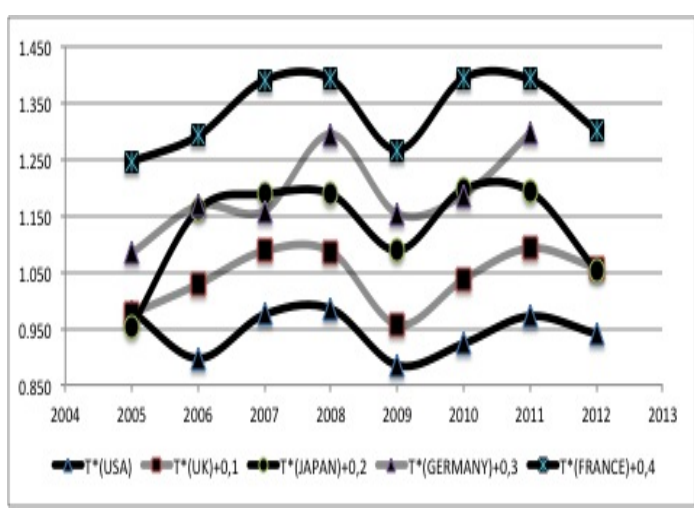

Fig. 2 Translated fragility indicator $T^{*}$ per year for each country. 


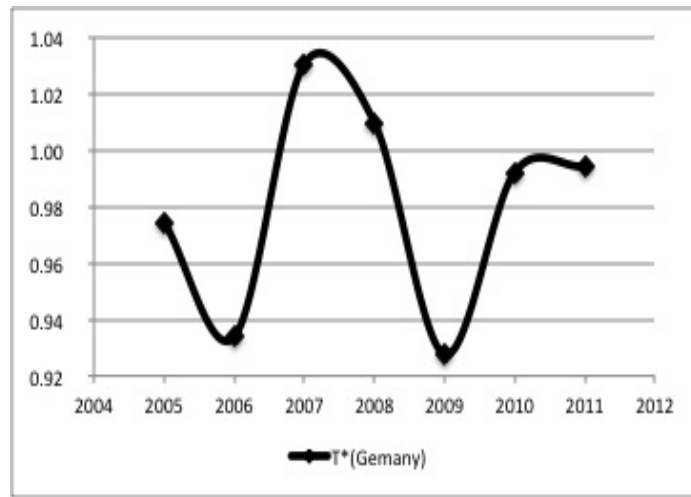

Fig. 3 The fragility indicator $T^{*}$ for Germany with $R^{A}=$ $R^{D}+R O O A$.

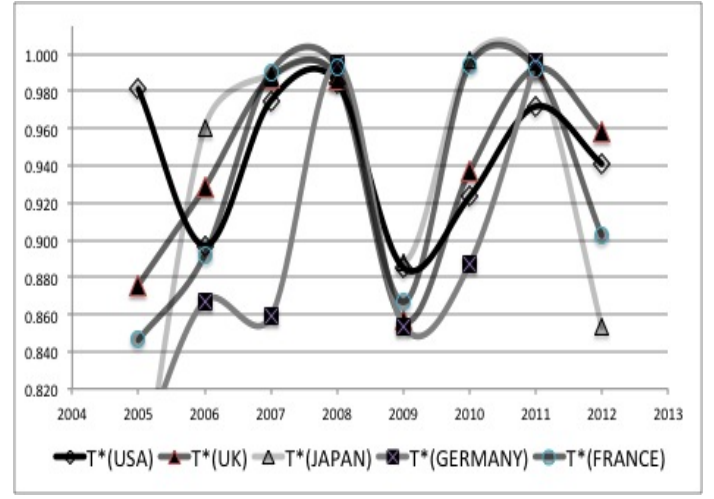

Fig. 5 The fragility indicator $T^{*}$ per year for each country.

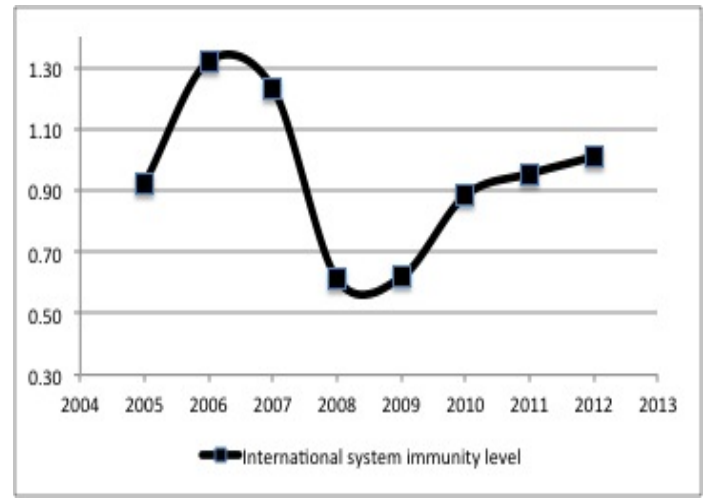

Fig. 7 The scaled immunity level $100\left(T-T^{*}\right)$ per year of the whole system.

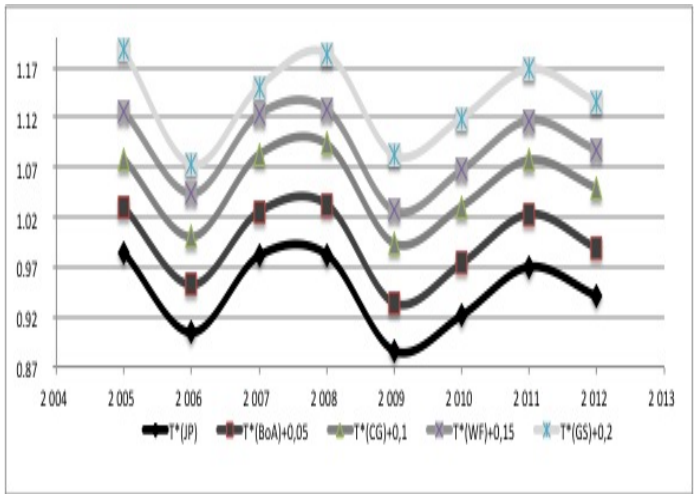

Fig. 4 The fragility indicator $T^{*}$ per year of each American bank.

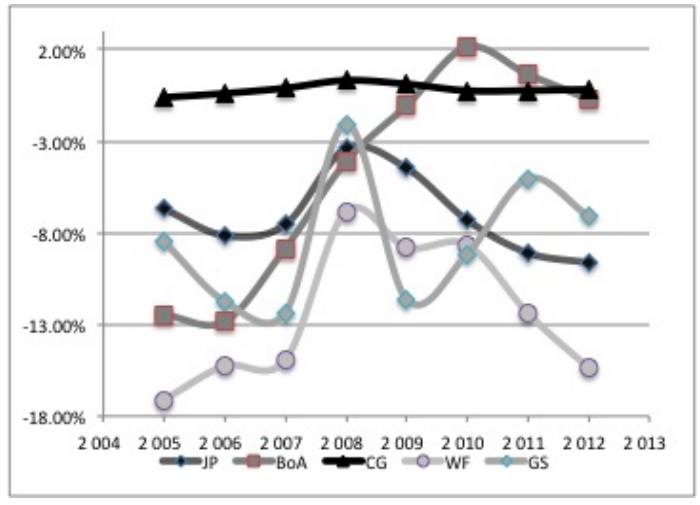

Fig. 6 Threshold $\Re$ per year of American banks.

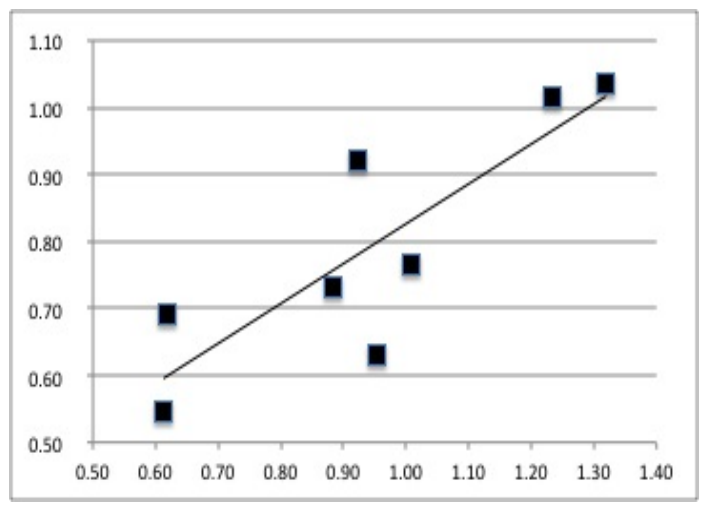

Fig. 8 The normalized portfolio market approximated as a linear function of the immunity level (on the $x$-axis). 


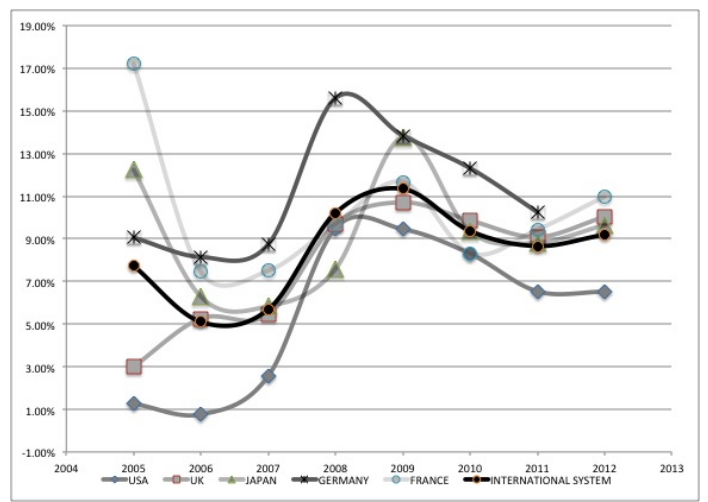

Fig. 9 Threshold capital ratio $\Re^{* 1.3 \%}$ per year by country.

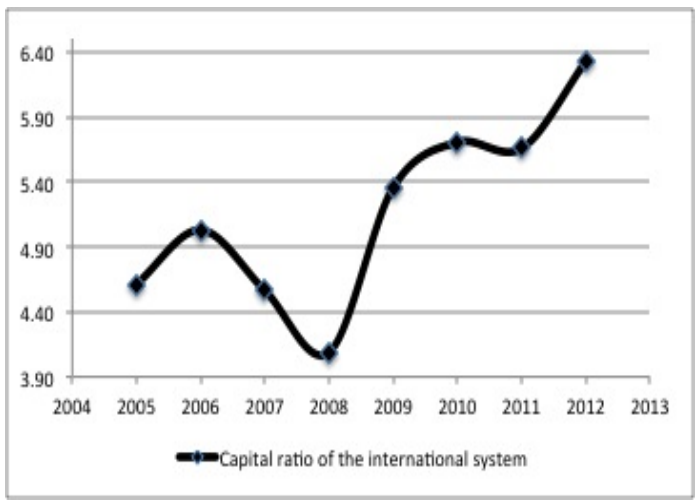

Fig. 10 Average capital ratio $E / A$ for the whole system.

\section{References}

1. Acharya V.,2009, A theory of systemic risk and design of prudential bank regulation, Journal of Financial Stability 5 , 224-255.

2. Acharya, V., L.H. Pedersen, T. Philippon and M. Richardsony, 2010, Measuring systemic risk, working paper, New York University.

3. Allen F. and D. Gale, 2000, Financial contagion, Journal of Political Economy, 108, 1-33.

4. Basel Committee on Banking Supervision , 2010, Basel III: A global regulatory framework for more resilient banks and banking systems.

5. Bernanke B., 2009, Financial reform to address systemic risk, Federal Reserve.

6. Bertrand M., A. Schoar and D. Thesmar, 2007, Banking deregulation and industry structure: Evidence from the French banking reforms of 1985, Journal of Finance 62, 597-628.

7. Slovik, P. and B. Cournde, 2011, Macroeconomic impact of Basel III, working paper, OECD Economics Department.

8. Brei M., L. Gambacorta and G. von Pete, 2012, Rescue packages and bank lending, Journal of Banking and Finance, $37,490505$.

9. Campello M., J.R. Graham and C.R. Harvey, 2010, The real effect of financial constraints: Evidence from a financial crisis, Journal of Financial Economics, 97, 470487.

10. Cerasia V., S. Daltungb, 2000, The optimal size of a bank: Costs and benefits of diversification, European Economic Review, 44, 17011726.

11. Cont R., A. Moussa and E.B. Santos, 2010, Network structure and systemic risk in banking systems, working paper, Imperial College London.

12. De Bandt O. and P. Hartmann, 2000, Systemic risk: A survey, working paper, ECB.

13. Diamond D. W. and R. G. Rajan, 2012, Illiquid banks, financial stability, and interest rate policy, Journal of Political Economy, 120, 552-591.

14. Elsinger H., A. Lehar and M. Summer, 2006, Risk assessment for banking systems, Management Science, 52, $1301-1314$.

15. Engle, R.F., E. Jondeau and M. Rockinger, 2012, Systemic risk in Europe, working paper, Swiss Finance Institute.

16. Hyun Song Shin, 2010, Macroprudential policies beyond Basel III, working paper, Princeton University.

17. Kragh-Srensen K., 2012, Optimal capital adequacy ratios for Norwegian banks, working paper, Norges Bank.

18. Kim T. and V. Mangla, 2012, Optimal capital regulation with two banking sectors, Working paper, Northwestern University.

19. Krasa S. and A. Villamil, 1992, A Theory of optimal bank size, Oxford Economic Papers.

20. Kabanov Y. and E. Lépinette , 2012. Essential supremum with respect to a random partial order. To appear in Journal of Mathematical Economics.

21. Hartmann P., S. Straetmans and C. de Vries, 2005, Banking system stability: A cross atlantic perspective, working paper, NBER.

22. Gauthier C., A. Lehar and M. Souissi, 2010, Macroprudential capital requirements and systemic risk, working paper, Bank of Canada.

23. Miles D., J. Yang and G. Marcheggiano, 2011, Optimal bank capital, working paper, Bank of England.

24. Minca A. and H. Amini, 2012, Mathematical modeling of systemic risk, Advances in network analysis and its applications, Springer Verlag. 
25. Morrison A. D., and L. White, 2005, Crises and capital requirements in banking, American Economic Review, 95, 1548-1572

26. Philippon T. and P. Schnable, 2013, Efficient recapitalization, Journal of Finance, 68, 1-42.

27. Reinhart, C. and K. Rogoff, 2009, This time is different: Eight centuries of financial folly, Princeton University Press.

28. Schanz J., 2011, A joint calibration of bank capital and liquidity ratios, working paper, Bank of England.

29. Tarashev N., C. Borio and K. Tsatsaronis, 2009, The systemic importance of financial institutions, BIS Quarterly Review, 75-87.

30. Yoshino N., T. Hirano and K. Miura, 2009, The optimal Basel capital requirement to cope with pro-cyclicality: A theoretical approach, Financial Services Agency, Government of Japan. 